4

$5 \quad \mathrm{Hua} \mathrm{Su}^{1, \#}$, Lin $\mathrm{Zhou}^{2, \#}, \mathrm{Na} \mathrm{Li}^{1}$, Guowen Wang ${ }^{1}$, Lingfang $\mathrm{Wu}^{1}$, Xiuqing $\mathrm{Ma}^{1}$, Kejing

$6 \quad$ Ying ${ }^{1, *}$ and Ruifeng Zhang, ${ }^{1, *}$

7

8

9 School of Medicine, 3 East Qingchun Road, Hangzhou, China.

\section{Transcriptome-wide map of $\mathbf{m}^{6} \mathrm{~A}$ circRNAs identified in hypoxic pulmonary} hypertension rat model

\section{Short title: $\mathbf{m}^{6} \mathrm{~A}$ circRNAs in hypoxic pulmonary hypertension}

\section{${ }^{1}$ Department of Respiratory medicine, Sir Run Run Shaw Hospital, Zhejiang University} 2Department of Gastroenterology, First Affiliated Hospital of Zhengzhou University, Zhengzhou, China.

${ }^{*}$ Correspondence: Ruifeng Zhang, e-mail: zhangruifeng@zju.edu.cn; Kejing Ying, email: 3197061@zju.edu.cn.

${ }^{\#}$ These two authors contribute equally to this work.

19

0

1

2

23




\section{Abstract}

Hypoxic pulmonary hypertension (HPH) is a lethal disease. CircRNAs and $\mathrm{m}^{6} \mathrm{~A}$ circRNAs have been reported to be associated with cancer progression, but the expression profiling of $\mathrm{m}^{6} \mathrm{~A}$ circRNAs has not been identified in HPH. This study was to investigate the transcriptome-wide map of $\mathrm{m}^{6} \mathrm{~A}$ circRNAs in HPH. In this study, hypoxia-induced PH rat model was established. Total RNA was extracted and purified from lungs of rats, then circRNAs were detected and annotated by RNA-seq analysis. $\mathrm{m}^{6} \mathrm{~A}$ RNA Immunoprecipitation (MeRIP) was performed following rRNA depletion, and RNA-seq library was constructed. CircRNA-miRNA-mRNA co-expression network was also constructed. In vitro, total $\mathrm{m}^{6} \mathrm{~A}$ was measured. $\mathrm{m}^{6} \mathrm{~A}$ circXpo6 and $\mathrm{m}^{6} \mathrm{~A}$ circTmtc3 were detected in pulmonary artery smooth muscle cells (PASMCs) and pulmonary artery endothelial cells (PAECs) exposed to $21 \% \mathrm{O}_{2}$ and $1 \% \mathrm{O}_{2}$ for $48 \mathrm{~h}$, respectively. $\mathrm{m}^{6} \mathrm{~A}$ abundance in 166 circRNAs was significantly upregulated and $\mathrm{m}^{6} \mathrm{~A}$ abundance in 191 circRNAs was significantly downregulated in lungs of HPH rats. $\mathrm{m}^{6} \mathrm{~A}$ abundance in circRNAs was significantly reduced in hypoxia in vitro. $\mathrm{m}^{6} \mathrm{~A}$ circRNAs were mainly derived from single exons of protein-coding genes. $\mathrm{m}^{6} \mathrm{~A}$ influenced the circRNA-miRNA-mRNA co-expression network in hypoxia. $\mathrm{m}^{6} \mathrm{~A}$ circXpo6 and $\mathrm{m}^{6} \mathrm{~A}$ circTmtc 3 were downregulated in hypoxia. In general, our study firstly identified the transcriptome-wide map of $\mathrm{m}^{6} \mathrm{~A}$ circRNAs in HPH. $\mathrm{m}^{6} \mathrm{~A}$ level in circRNAs was decreased in lungs of HPH rats and in PASMCs and PAECs exposed to hypoxia. Downregulated or upregulated $\mathrm{m}^{6} \mathrm{~A}$ level influenced circRNA-miRNAmRNA co-expression network in HPH. Moreover, we firstly identified two downregulated $\mathrm{m}^{6} \mathrm{~A}$ circRNAs in HPH: circXpo6 and circTmtc3. We suggested that $\mathrm{m}^{6} \mathrm{~A}$ circRNAs may be used as a potential diagnostic marker or therapy target in the future.

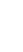




\section{Author summary}

$\mathrm{HPH}$ is a disease with great morbidity and mortality. It is often caused by chronic hypoxic lung diseases, such as chronic obstructive pulmonary disease and interstitial lung diseases. It lacks effective therapy methods so far. CircRNAs are a type of noncoding RNAs and can be used as biomarkers because they are differentially enriched in specific cell types or tissues and not easily degraded. $\mathrm{m}^{6} \mathrm{~A}$ is identified as the most universal modification on non-coding RNAs in eukaryotes. CircRNAs can be modified by $\mathrm{m}^{6} \mathrm{~A} \cdot \mathrm{m}^{6} \mathrm{~A}$ circRNAs in HPH is not well understood yet. Here we identify the transcriptome-wide map of $\mathrm{m}^{6} \mathrm{~A}$ circRNAs in $\mathrm{HPH}$. We elucidate that $\mathrm{m}^{6} \mathrm{~A}$ level in circRNAs is decreased in lungs of HPH rats and in PASMCs and PAECs exposed to hypoxia. We find that downregulated or upregulated $\mathrm{m}^{6} \mathrm{~A}$ level influences circRNAmiRNA-mRNA co-expression network in HPH. Moreover, we are the first to identify two downregulated $\mathrm{m}^{6} \mathrm{~A}$ circRNAs in HPH: circXpo6 and circTmtc3. We suggest that $\mathrm{m}^{6} \mathrm{~A}$ circRNAs may be used as a potential diagnostic marker or therapy target in the future.

.

9

80

81

\section{2}

83

84

85

86




\section{Introduction}

Pulmonary hypertension $(\mathrm{PH})$ is a lethal disease and defined as an increase in the mean pulmonary arterial pressure $\geq 25 \mathrm{mmHg}$ at rest, as measured by right heart catheterization (1). Hypoxic pulmonary hypertension (HPH) belongs to group III PH according to the comprehensive clinical classification of $\mathrm{PH}$, normally accompanied by severe chronic obstructive pulmonary disease (COPD) and interstitial lung diseases (2). $\mathrm{HPH}$ is a progressive disease induced by chronic hypoxia $(\mathrm{CH})(1)$. $\mathrm{CH}$ triggers overproliferation of pulmonary artery endothelial cells (PAECs) and pulmonary artery smooth muscle cells (PASMCs), and activation of quiescent fibroblasts, the hallmark of $\mathrm{HPH}(1,3)$. The pathological characteristics of $\mathrm{HPH}$ are pulmonary vascular remolding, pulmonary hypertension, and right ventricular hypertrophy (RVH) (4). So far there is no effective therapy for HPH (2). More effective therapeutic targets are needed to be discovered.

Circular RNAs (circRNAs) were firstly found abundant in eukaryotes using RNA-seq approach (5-7). Pre-mRNA is spliced with the 5' and 3' ends, forming a 'head-to-tail' splice junction, then circRNAs are occurred (5). According to the genome origin, circRNAs may be classified into four different subtypes: exonic circRNA (ecircRNA), intronic circRNA (ciRNA), exon-intron circRNA (EIciRNA) and tRNA introns circRNA (tricRNA) (5). CircRNAs are reported to play crucial roles in miRNA binding, protein binding, regulation of transcription, and post-transcription $(5,8)$. Recent reports indicated that circRNAs can translate to proteins $(8,9)$. Moreover, circRNAs are widely expressed in human umbilical venous endothelial cells when stimulated by hypoxia (10, 11). Up to date, only a few reports mentioned PH-associated circRNAs. CircRNAs expression profile is demonstrated in HPH and chronic thromboembolic pulmonary hypertension (12). However, it is still unknown that the post-transcript modification of circRNAs in HPH. 
$121 \mathrm{~N}^{6}$-methyladenosine $\left(\mathrm{m}^{6} \mathrm{~A}\right)$ is regarded as one part of "epitranscriptomics" and identified as the most universal modification on mRNAs and noncoding RNAs (ncRNAs) in eukaryotes $(13,14)$. DRm ${ }^{6} \mathrm{ACH}$ (D denotes A, U or G; R denotes A, G; $\mathrm{H}$ denotes $\mathrm{A}, \mathrm{C}$, or $\mathrm{U}$ ) is a consensus motif occurred in $\mathrm{m}^{6} \mathrm{~A}$ modified RNAs (15-17). $\mathrm{m}^{6} \mathrm{~A}$ modification is mainly enriched around the stop codons, at 3'untranslated regions (3' UTRs) and within internal long exons (17-19). Several catalyzed molecules act as "writers", "readers", and "erasers"' to regulate the $\mathrm{m}^{6} \mathrm{~A}$ modification status (14). The methyltransferase complex is known as writers, including methyltransferase-like-3, -14 and -16 (METTL3/METTL14/METTL16), Wilms tumour 1-associated protein (WTAP), RNA binding motif protein 15 (RBM15), vir like $\mathrm{m}^{6} \mathrm{~A}$ methyltransferase associated (KIAA1429) and zinc finger CCCH-type containing 13 (ZC3H13), appending $\mathrm{m}^{6} \mathrm{~A}$ on $\mathrm{DRACH}(17,20,21)$. METTL3 is regarded as the core catalytically active subunit, while METTL14 and WTAP play a structural role in METTL3's catalytic activity $(18,22)$. The "erasers", fat mass and obesity related protein (FTO) and alkylation repair homolog 5 (ALKBH5), catalyze the $\mathrm{N}$-alkylated nucleic acid bases oxidatively demethylated (22). The "readers", the YT521-B homology (YTH) domain-containing proteins family includes YTHDF (YTHDF1, YTHDF2, YTHDF3), YTHDC1, and YTHDC2, specifically recognizes $\mathrm{m}^{6} \mathrm{~A}$ and regulates splicing, localization, degradation and translation of RNAs $(14,22,23)$. The YTHDF1 and YTHDF2 crystal structures forms an aromatic cage to recognize $\mathrm{m}^{6} \mathrm{~A}$ sites in cytoplasm (24). YTHDC1 is the nuclear reader and YTHDC2 binds $\mathrm{m}^{6} \mathrm{~A}$ under specific circumstances or cell types (24). Hypoxia may alter the balance of writers-erasersreaders and induce tumor growth, angiogenesis, and progression $(25,26)$.

Interestingly, circRNAs can be $\mathrm{m}^{6} \mathrm{~A}$-modified. $\mathrm{m}^{6} \mathrm{~A}$ circRNAs displayed cell-typespecific methylation patterns in human embryonic stem cells (hESCs) and HeLa cells (14). CircRNAs contained $\mathrm{m}^{6} \mathrm{~A}$ modifications are likely to promote protein translation in a cap-independent pattern (9). However, $\mathrm{m}^{6} \mathrm{~A}$ circRNAs has not been elucidated in $\mathrm{HPH}$ yet. Here we are the first to identify the correlation between $\mathrm{m}^{6} \mathrm{~A}$ modification and circRNAs abundance in HPH. 


\section{Results}

$m^{6} A$ level of circRNAs was reduced in HPH rats and most circRNAs contained one $\mathbf{m}^{6} \mathrm{~A}$ peak

3 weeks treatment by hypoxia resulted in right ventricular systolic pressure (RVSP) elevating to $42.23 \pm 1.96 \mathrm{mmHg}$ compared with $27.73 \pm 1.71 \mathrm{mmHg}$ in the control $(\mathrm{p}$ $<0.001$, Fig 1A and 1B). RVH was indicated by the increase of the ratio of the right ventricle $(\mathrm{RV})$, left ventricular plus ventricular septum $(\mathrm{LV}+\mathrm{S})[\mathrm{RV} /(\mathrm{LV}+\mathrm{S})]$ compared with the control $(0.25 \pm 0.03$ vs. $0.44 \pm 0.04, p=0.001$, Fig 1C). The medial wall of the pulmonary small arteries was also significantly thickened $(19.28 \pm 2.19 \%$ vs. $39.26 \pm 5.83 \%$, p < 0.001, Fig 1D and 1E). Moreover, in the normoxia group, 53.82 $\pm 3.27 \%$ of the arterioles were non-muscularized $(\mathrm{NM})$ vessels, and $25.13 \pm 1.83 \%$ were fully muscularized (FM) vessels. In contrast, partially muscularized vessels (PM) and FM vessels showed a greater proportion $(32.88 \pm 3.15 \%$ and $41.41 \pm 3.35 \%)$ in HPH rats, while NM vessels occupied a lower proportion $(25.71 \pm 2.55 \%)($ Fig 1F). Fig 1G displayed the heatmap of $\mathrm{m}^{6} \mathrm{~A}$ circRNAs expression profiling in normoxia $(\mathrm{N})$ and hypoxia (HPH). $\mathrm{m}^{6} \mathrm{~A}$ abundance in 166 circRNAs was significantly upregulated. Meanwhile, $\mathrm{m}^{6} \mathrm{~A}$ abundance in 191 circRNAs was significantly downregulated (S1

Table, filtered by fold change $\geq 4$ and $\mathrm{p} \leq 0.00001$ ). Lungs of $\mathrm{N}$ and HPH rats were selected to measure $\mathrm{m}^{6} \mathrm{~A}$ abundance in purified circRNAs. The $\mathrm{m}^{6} \mathrm{~A}$ level in total circRNAs isolated from lungs of HPH rats was lower than that from controls (Fig 1H). Moreover, over $50 \%$ circRNAs contained only one $\mathrm{m}^{6} \mathrm{~A}$ peak either in lungs of $\mathrm{N}$ or HPH rats (Fig 1I).

$\mathrm{m}^{6} \mathrm{~A}$ circRNAs were mainly from protein-coding genes spanned single exons in $\mathbf{N}$ and HPH groups

We analyzed the distribution of the parent genes of total circRNAs, $\mathrm{m}^{6} \mathrm{~A}$-circRNAs, and non- $\mathrm{m}^{6} \mathrm{~A}$ circRNAs in $\mathrm{N}$ and $\mathrm{HPH}$, respectively. $\mathrm{N}$ and $\mathrm{HPH}$ groups showed a similar genomic distribution of $\mathrm{m}^{6} \mathrm{~A}$ circRNAs and non- $\mathrm{m}^{6} \mathrm{~A}$ circRNAs (Fig $2 \mathrm{~A}$ and 
181 from protein-coding genes in both groups. A previous report indicated that most

182

183 circRNAs originated from protein-coding genes spanned two or three exons (14). While in our study, over $50 \%$ and $40 \%$ of total circRNAs from protein-coding genes spanned one exon in $\mathrm{N}$ and $\mathrm{HPH}$ groups, respectively (Fig 2C and 2D). Similarly, $\mathrm{m}^{6} \mathrm{~A}$ circRNAs and non- $\mathrm{m}^{6} \mathrm{~A}$ circRNAs were mostly encoded by single exons. Therefore, it was indicated that $\mathrm{m}^{6} \mathrm{~A}$ methylation was abundant in circRNAs originated from single exons in $\mathrm{N}$ and $\mathrm{HPH}$ groups.

\section{The distribution and functional analysis for host genes of circRNAs with differentially expressed (DE) $\mathrm{m}^{6} \mathrm{~A}$ peaks}

The length of DE $\mathrm{m}^{6} \mathrm{~A}$ circRNAs was mostly enriched in 1-10000 bps (Fig 3A). The host genes of upregulated $\mathrm{m}^{6} \mathrm{~A}$ circRNAs were located in chromosome 1, 2 and 10, while the downregulated parts were mostly located in chromosome 1, 2 and 14 (Fig 3B).

Gene ontology (GO) analysis and Kyoto Encyclopedia of Genes and Genomes (KEGG) pathway analysis were performed to explore the host genes of circRNAs with DE $\mathrm{m}^{6} \mathrm{~A}$ peaks. In the GO analysis (Fig 3C, left), the parent genes of circRNAs with upregulated $\mathrm{m}^{6} \mathrm{~A}$ peaks were enriched in the protein modification by small protein conjugation or removal and macromolecule modification process in the biological process (BP). Organelle and membrane-bounded organelle were also the two largest parts in the cellular component (CC) analysis. Binding and ion binding were the two main molecular functions (MF). The top 10 pathways from KEGG pathway analysis were selected in the bubble chart (Fig 3C, right). Among them, the oxytocin signaling pathway, protein processing in endoplasmic reticulum and cGMP-PKG signaling pathway were the top 3 pathways involved. In addition, vascular smooth muscle contraction pathway was the most associated pathway in PH progression (27).

In Fig 3D left, the parent genes of circRNAs with downregulated $\mathrm{m}^{6} \mathrm{~A}$ peaks were mainly enriched in the cellular protein modification process and protein modification 
process in BP. Organelle and membrane-bounded organelle made up the largest proportion in the $\mathrm{CC}$ classification. The MF analysis was focused on receptor signaling protein activity and protein binding. The parent genes of circRNAs with decreased $\mathrm{m}^{6} \mathrm{~A}$ peaks were mainly involved in the tight junction and lysine degradation in the KEGG pathway analysis (Fig 3D, right).

\section{$\mathrm{m}^{6} \mathrm{~A}$ level of circRNAs and circRNAs abundance were influenced by hypoxia} $360 \mathrm{~m}^{6} \mathrm{~A}$ circRNAs were detected in N and HPH groups. 49\% of circRNAs were only modified by $\mathrm{m}^{6} \mathrm{~A}$ in $\mathrm{N}$, and $54 \%$ of circRNAs were only modified by $\mathrm{m}^{6} \mathrm{~A}$ in $\mathrm{HPH}($ Fig 4A). To explore whether $\mathrm{m}^{6} \mathrm{~A}$ methylation would influence circRNAs expression level, expression of the 360 common $\mathrm{m}^{6} \mathrm{~A}$ circRNAs were identified. More circRNAs tended to decrease in HPH compared to $\mathrm{N}$ (Fig 4B). Moreover, expression of $\mathrm{m}^{6} \mathrm{~A}$ circRNAs was significantly downregulated compared with non- $\mathrm{m}^{6} \mathrm{~A}$ circRNAs in hypoxia, suggesting that $\mathrm{m}^{6} \mathrm{~A}$ may downregulate the expression of circRNAs in hypoxia (Fig $4 C, p=0.0465)$.

\section{Construction of a circRNA-miRNA-mRNA co-expression network in HPH}

We found 76 upregulated circRNAs with increased $\mathrm{m}^{6} \mathrm{~A}$ abundance, and 107 downregulated circRNAs with decreased $\mathrm{m}^{6} \mathrm{~A}$ abundance (Fig 5A, S2 Table). As known, circRNAs were mostly regarded as a sponge for miRNAs and regulated the expression of corresponding target genes of miRNAs (28). To explore whether circRNAs with $\mathrm{DE} \mathrm{m}^{6} \mathrm{~A}$ abundance influence the availability of miRNAs to target genes, we selected DE circRNAs with increased or decreased $\mathrm{m}^{6} \mathrm{~A}$ abundance. GO enrichment analysis and KEGG pathway analysis were also performed to analyze target mRNAs. Target mRNAs displayed similar GO enrichment in the two groups (Fig 5B and 5C). Two main functions were determined in BP analysis: positive regulation of biological process and localization. Intracellular and intracellular parts make up the largest proportion in CC part. Target mRNAs were mostly involved in protein binding and binding in MF part. In the KEGG pathway analysis, the top 10 most enriched pathways were selected (Fig 5D and 5E). Wnt and FoxO signaling pathways were 
reported to be involved in PH progression (29-31). Then, we analyzed the target genes involved in these two pathways (S1 Fig and S2 Fig). SMAD4 was associated with PH and involved in Wnt signaling pathways. MAPK3, SMAD4, TGFBR1, and CDKN1B were involved in FoxO signaling pathways. To explore the influence of circRNAmiRNA regulation on $\mathrm{PH}$-associated genes expression, we constructed a circRNAmiRNA-mRNA network, integrating matched expression profiles of circRNAs, miRNAs and mRNAs (Fig 5F and 5G). MicroRNAs sponged by the target genes of interest were analyzed. MiR-125a-3p, miR-23a-5p, miR-98-5p, let-7b-5p, let-7a-5p, let-7g-5p, and miR-205 were analyzed because they were reported to be associated with PH $(32,33)$. We filtered the key mRNAs and miRNAs, and founded that the two circRNAs were the most enriched, which were originated from chr1:204520403204533534- (Xpo6) and chr7:40223440-40237400- (Tmtc3).

$\mathrm{m}^{6} \mathrm{~A}$ circXpo6 and $\mathrm{m}^{6} \mathrm{~A}$ circTmtc3 were downregulated in PASMCs and PAECs in hypoxia

$\mathrm{m}^{6} \mathrm{~A}$ abundance was significantly reduced in PASMCs and PAECs when exposed to hypoxia $(0.107 \% \pm 0.007$ vs. $0.054 \% \pm 0.118, \mathrm{p}=0.023$ in PASMCs; $0.114 \% \pm 0.011$ vs. $0.059 \% \pm 0.008, \mathrm{p}=0.031$ in PAECs, Fig 6A). $\mathrm{m}^{6} \mathrm{~A}$ abundance in circRNAs was lower than it in mRNAs $(0.1-0.4 \%)(17,18)$. Next, we confirmed the back-splicing of circXpo6 and circTmtc3 by CIRI software. The sequence of linear Xpo6 and Tmtc3 mRNA was analyzed. Then we identified that circXpo6 was spliced form exon 7, 8, and 9 of Xpo6. CircTmtc3 was spliced form exon 8, 9, 10, and 11 (Fig 6B). Using cDNA and genomic DNA (gDNA) from PASMCs and PAECs as templates, circXpo6 and circTmtc 3 were only amplified by divergent primers in cDNA, while no product was detected in gDNA (Fig 6C). To identify whether circXpo6 and circTmtc3 were modified by $\mathrm{m}^{6} \mathrm{~A}$, we performed $\mathrm{m}^{6} \mathrm{~A}$ RNA Immunoprecipitation (MeRIP)-RT-PCR and MeRIP quantitative RT-PCR (MeRIP-qRT-PCR) to detect the expression of circXpo6 and circTmtc3 (Fig 6D and 6E). $\mathrm{m}^{6} \mathrm{~A}$ circXpo6 and $\mathrm{m}^{6} \mathrm{~A}$ circTmtc 3 were significantly decreased in PASMCs and PAECs when exposed to hypoxia $(\mathrm{p}=0.002$, and $p=0.015$ in PASMCs and $p=0.02$, and $p=0.047$ in PAECs) 


\section{Discussion}

273 In this study, we identified the transcriptome-wide map of $\mathrm{m}^{6} \mathrm{~A}$ circRNAs in hypoxic pulmonary hypertension. On the whole, we found that $\mathrm{m}^{6} \mathrm{~A}$ level in circRNAs was reduced in lungs when exposed to hypoxia. $\mathrm{m}^{6} \mathrm{~A}$ circRNAs were mainly derived from single exons of protein-coding genes in $\mathrm{N}$ and HPH. $\mathrm{m}^{6} \mathrm{~A}$ abundance in circRNAs was downregulated in hypoxia in vitro. $\mathrm{m}^{6} \mathrm{~A}$ influenced the circRNA-miRNA-mRNA coexpression network in hypoxia. Moreover, circXpo6 and circTmtc3 were the novel

$\mathrm{m}^{6} \mathrm{~A}$ plays important roles in various biological processes. $\mathrm{m}^{6} \mathrm{~A}$ is associated with cancer progression, promoting the proliferation of cancer cells and contributing to the cancer stem cell self-renewal $(18,21)$. Lipid accumulation was reduced in hepatic cells when $\mathrm{m}^{6} \mathrm{~A}$ abundance in peroxisome proliferator-activator $(P P a R)$ was decreased (34). Enhanced $\mathrm{m}^{6} \mathrm{~A}$ level of mRNA contributed to compensated cardiac hypertrophy (35). Also, $\mathrm{m}^{6} \mathrm{~A}$ modification of lincRNA 1281 was necessary for mESC differentiation (36).

Although it has been reported that $\mathrm{m}^{6} \mathrm{~A}$ mRNAs were influenced by hypoxia, there is no report about $\mathrm{m}^{6} \mathrm{~A}$ circRNAs in $\mathrm{HPH}$ yet. Up to now, no consistent conclusion was reached about the link between $\mathrm{m}^{6} \mathrm{~A}$ and hypoxia. Previous reports found that the $\mathrm{m}^{6} \mathrm{~A}$ abundance in mRNA was increased under hypoxia stress in HEK293T cells and cardiomyocytes $(37,38)$. The increased $\mathrm{m}^{6} \mathrm{~A}$ level stabilized the mRNAs of Glucose Transporter 1 (Glut1), Myc proto-oncogene bHLH transcription factor (Myc), Dual Specificity Protein Phosphatase 1 (Dusp1), Hairy and Enhancer of Split 1 (Hes1), and Jun Proto-Oncogene AP-1 Transcription Factor Subunit (Jun) without influencing their protein level (37). In contrast, another reported that $\mathrm{m}^{6} \mathrm{~A}$ level of total mRNA was decreased when human breast cancer cell lines were exposed to $1 \% \mathrm{O}_{2}(26)$. Hypoxia increased demethylation by stimulating hypoxia-inducible factor (HIF)-1 $\alpha$ - and HIF- 
mRNA in hypoxia/reoxygenation (H/R)-induced autophagy in ischemic diseases (38). Our study found that $\mathrm{m}^{6} \mathrm{~A}$ abundance in total circRNAs was decreased by hypoxia exposure. Moreover, our study indicated that circXpo6 and circTmtc3 were the novel identified circRNAs modified by $\mathrm{m}^{6} \mathrm{~A}$ in $\mathrm{HPH} . \mathrm{m}^{6} \mathrm{~A}$ abundance in circXpo6 and circTmtc3 was decreased in hypoxia. It is probably because of HIF-dependent and ALKBH5-mediated $\mathrm{m}^{6} \mathrm{~A}$ demethylation (26).

Previous reports indicated that $\mathrm{m}^{6} \mathrm{~A}$ methylation close to $3^{\text {'UTR }}$ and stop codon of mRNA is inversely correlated with gene expression $(14,39)$. Low $\mathrm{m}^{6} \mathrm{~A}$ level is negatively associated with circRNAs expression, while high $\mathrm{m}^{6} \mathrm{~A}$ level is not linked to circRNAs expression in hESCs and HeLa cells (14). Consistent with the previous reports $(14,39)$, our study found that $\mathrm{m}^{6} \mathrm{~A}$ reduced the total circRNAs abundance in hypoxia. Surprisingly, the expression of circXpo6 and circTmtc3 was decreased with the downregulated $\mathrm{m}^{6} \mathrm{~A}$ level. No associated reports could confirm this phenomenon yet. Therefore, we suspected that $\mathrm{m}^{6} \mathrm{~A}$ may influence the expression of circXpo6 and circTmtc3 through other pathways. It needs further validation.

Competing endogenous RNA (ceRNA) mechanism was proposed that mRNAs, pseudogenes, lncRNAs and circRNAs interact with each other by competitive binding to miRNA response elements (MREs) $(40,41) \cdot \mathrm{m}^{6} \mathrm{~A}$ acts as a post-transcript regulation of circRNAs and influences the expression of circRNAs, thus we suggested that $\mathrm{m}^{6} \mathrm{~A}$ could also regulate the circRNA-miRNA-mRNA co-expression network. When the circRNAs were classified, we found that these downstream targets regulated by circRNA-miRNA of interest were mostly enriched in PH-associated Wnt and FoxO signaling pathways $(30,31)$. The $\mathrm{Wnt} / \beta$-catenin $(\mathrm{bC})$ pathway and $\mathrm{Wnt} /$ planar cell polarity (PCP) pathway are the two most critical Wnt signaling pathways in $\mathrm{PH}(30)$. As known, the two important cells associated with HPH are PASMCs and PAECs (1, 3). The growth of PASMCs was increased when Wnt/bC and Wnt/PCP pathways were activated by platelet derived growth factor beta polypeptide b (PDGF-BB) (30, 42). In addition, the proliferation of PAECs was enhanced when $\mathrm{Wnt} / \mathrm{bC}$ and $\mathrm{Wnt} / \mathrm{PCP}$ 
331 pathways were activated by bone morphogenetic protein 2 (BMP2). Furthermore, the

332 FoxO signaling pathway is associated with the apoptosis-resistant and 333 hyperproliferative phenotype of PASMCs (31). Reactive oxygen species (ROS) is increased by hypoxia and activates AMPK-dependent regulation of FoxO1 expression, resulting in increased expression of catalase in PASMCs (43). Our study firstly uncovered that $\mathrm{m}^{6} \mathrm{~A}$ influenced the stability of circRNAs, thus affecting the binding of circRNAs and miRNA, resulting in the activation of Wnt and FoxO signaling pathways.

However, limitations still exist in the study. First, we did not analyze the $\mathrm{m}^{6} \mathrm{~A}$ level between circRNAs and the host genes. Second, the exact mechanism of hypoxia influences $\mathrm{m}^{6} \mathrm{~A}$ was not demonstrated. Lastly, the function of circXpo6 and circTmtc3 in HPH was not elaborated.

In conclusion, our study firstly identified the transcriptome-wide map of $\mathrm{m}^{6} \mathrm{~A}$ circRNAs in HPH. $\mathrm{m}^{6} \mathrm{~A}$ level in circRNAs was decreased in lungs of HPH and in PASMCs and PAECs exposed to hypoxia. $\mathrm{m}^{6} \mathrm{~A}$ level influenced circRNA-miRNA-mRNA coexpression network in HPH. Moreover, we firstly identified two downregulated $\mathrm{m}^{6} \mathrm{~A}$ circRNAs in HPH: circXpo6 and circTmtc3. We suggest that circRNAs can be used as biomarkers because it is differentially enriched in specific cell types or tissues and not easily degraded (6). Also, the aberrant $\mathrm{m}^{6} \mathrm{~A}$ methylation may contribute to tumor formation and $\mathrm{m}^{6} \mathrm{~A}$ RNAs may be a potential therapy target for tumor (17). Therefore, we suppose that $\mathrm{m}^{6} \mathrm{~A}$ circRNAs may also be used as a potential diagnostic marker or therapy target in HPH in the future. But more research is needed to validate this possibility.

\section{Materials and Methods}

\section{Hypoxia-induced PH rat model}

358 Sprague-Dawley rats (SPF, male, 180-200 g, 4 weeks) were obtained from the Animal normobaric normoxia $\left(\mathrm{FiO}_{2} 21 \%\right)$ or hypoxic chamber $\left(\mathrm{FiO}_{2} 10 \%\right)$ for 3 weeks $(3,44)$. 
Rats were then isoflurane-anesthetized and sacrificed. Lung and heart tissues were removed and immediately frozen at liquid nitrogen or fixed in $4 \%$ buffered paraformaldehyde solution. All experimental procedures were conducted in line with the principles approved by the Institutional Animal Care and Use Committee of Zhejiang University.

\section{RVSP and RVH}

RVSP was measured as below. Rats were isoflurane-anesthetized and right ventricle catheterization was performed through the right jugular using a pressure-volume loop catheter (Millar) as the previous reports (44-46). The ratio of [RV/ $(\mathrm{LV}+\mathrm{S})]$ was used as an index of RVH.

\section{Histological analysis}

Lung tissues were embedded in paraffin, sectioned at $4 \mu \mathrm{m}$ and stained with hematoxylin and eosin (H\&E) and $\alpha$-smooth muscle actin ( $\alpha$-SMA, 1:100, ab124964, Abcam, USA). The ratio of pulmonary small artery wall thickness and muscularization were calculated (3).

\section{Isolation and hypoxia-treatment of PASMCs and PAECs}

PASMCs and PAECs were isolated using the methods according to previous reports $(32,47,48)$. PASMCs and PAECs were cultured in Dulbecco's modified Eagle's medium (DMEM) supplemented with 10\% fetal bovine serum (FBS) and 20\% FBS for $48 \mathrm{~h}$, respectively $(32,49)$. The cells were incubated in a $37^{\circ} \mathrm{C}, 21 \% \mathrm{O}_{2}$ or $1 \% \mathrm{O}_{2}-5 \%$ $\mathrm{CO}_{2}$ humidified incubator. PASMCs at $70-80 \%$ confluence in 4 to 7 passages were used in experiments. PAECs at $80-90 \%$ confluence in 4 to 5 passages were used in experiments (50).

\section{RNA isolation and RNA-seq analysis of circRNAs}

Total RNA (10 mg) was obtained using TRIzol reagent (Invitrogen, Carlsbad, CA, USA) from lungs ( $1 \mathrm{~g}$ ) of control and HPH rats. The extracted RNAs were purified with Rnase 
R (RNR07250, Epicentre) digestion to remove linear transcripts. Paired-end reads were harvested from Illumina Hiseq Sequence after quality filtering. The reads were aligned to the reference genome (UCSC RN5) with STAR software. CircRNAs were detected and annotated with CIRI software(51). Raw junction reads were normalized to per million number of reads (RPM) mapped to the genome with log2 scaled.

\section{MeRIP and Library Preparation}

Total RNA was extracted as the methods described above. Then, rRNA was depleted following DNase I treatment. RNase $\mathrm{R}$ treatment (5 units $/ \mathrm{mg}$ ) was performed in duplicate with $5 \mathrm{mg}$ of rRNA-depleted RNA input. Fragmented RNA was incubated with anti-m ${ }^{6}$ A polyclonal antibody (Synaptic Systems, 202003) in IPP buffer for 2 hours at $4{ }^{\circ} \mathrm{C}$. The mixture was then incubated with protein $\mathrm{A} / \mathrm{G}$ magnetic beads ( 88802 , Thermo Fisher) at $4^{\circ} \mathrm{C}$ for an additional 2 hours. Then, bound RNA was eluted from the beads with $\mathrm{N}^{6}$-methyladenosine (PR3732, BERRY \& ASSOCIATES) in IPP buffer and extracted with Trizol reagent (15596026, Thermo Fisher). NEBNext ${ }^{\circledR}$ Ultra $^{\mathrm{TM}}$ RNA Library Prep Kit (E7530L, NEB) was used to construct RNA-seq library from immunoprecipitated RNA and input RNA. The $\mathrm{m}^{6} \mathrm{~A}-\mathrm{IP}$ and input samples were subjected to 150 bp paired-end sequencing on Illumina HiSeq sequencer. Methylated sites on circRNAs were identified by MetPeak software.

\section{Construction of circRNA-miRNA-mRNA co-expression network}

The circRNA-miRNA-mRNA co-expression network was based on the ceRNA theory that circRNA and mRNA shared the same MREs. Cytoscape was used to visualize the circRNA-miRNA-mRNA interactions based on the RNA-seq data. The circRNAmiRNA interaction and miRNA-mRNA interaction of interest were predicted by TargetScan and miRanda.

\section{Measurement of Total $\mathbf{m}^{6} \mathrm{~A}$, MeRIP-RT-PCR and MeRIP-qRT-PCR}

Total $\mathrm{m}^{6} \mathrm{~A}$ content was measured in $200 \mathrm{ng}$ aliquots of total RNA extracted from PASMCs and PAECs exposed to $21 \% \mathrm{O}_{2}$ and $1 \% \mathrm{O}_{2}$ for $48 \mathrm{~h}$ using an $\mathrm{m}^{6} \mathrm{~A}$ RNA 
methylation quantification kit (P-9005, Epigentek) according to the manufacturer's instructions. MeRIP (17-701, Millipore) was performed according to the manufacturer's instruction. A $1.5 \mathrm{~g}$ aliquot of anti-m ${ }^{6} \mathrm{~A}$ antibody (ABE572, Millipore) or anti-IgG (PP64B, Millipore) was conjugated to protein $\mathrm{A} / \mathrm{G}$ magnetic beads overnight at $4^{\circ} \mathrm{C}$. A $100 \mathrm{ng}$ aliquot of total RNA was then incubated with the antibody in IP buffer supplemented with RNase inhibitor and protease inhibitor. The RNA complexes were isolated through phenol-chloroform extraction (P1025, Solarbio) and analyzed via RT-PCR or qRT-PCR assays. Primers sequences were listed as follows: circXpo6, 5' TCTGGGAGACAAGGAAGCAG3' (forward) and 5' CAGGATGGGGATGGGCTG3' (reverse); circTmtc3, 5' TACCCATGTTCAGCCAGGTT3' (forward) and GAAGCCAAGCATTCACAGGA3' (reverse); linear Xpo6, 5' CTGTGTtTtGGGTCAGGAGC 3' (forward) and ATCGAGTTCCTCTAGCCTGC3' (reverse); linear Tmtc3, 5', ACTCTGCTGTGATTGGACCA3' (forward) and AGAAGAGGTTTGATGCGGGA3' (reverse).

\section{Data analysis}

3' adaptor-trimming and low quality reads were removed by cutadapt software (v1.9.3). Differentially methylated sites were identified by the R MeTDiff package. The read alignments on genome could be visualized using the tool IGV. DE circRNAs were identified by Student's $t$-test. GO and KEGG pathway enrichment analysis were performed for the corresponding parental mRNAs of the DE circRNAs. GO enrichment analysis was performed using the $\mathrm{R}$ topGO package. KEGG pathway enrichment analysis was performed according to a previous report (52). GO analysis included BP analysis, $\mathrm{CC}$ analysis, and MF analysis. MicroRNAs sponged by the target genes were predicted by TargetScan and microRNA. P values are calculated by DAVID tool for GO and KEGG pathway analysis. The rest statistical analyses were performed with SPSS 19.0 (Chicago, IL, USA) and GraphPad Prism 5 software (La Jolla, CA). N refers to number of samples in figure legends. The statistical significance was determined by 
451 Student's $t$-test (two-tailed) or two-sided Wilcoxon-Mann-Whiteney test. P $<0.05$ was considered statistically significant. All experiments were independently repeated at least three times.

\section{Acknowledgements}

We thanked all subjects who participated in this study.

\section{References}

1. Steven C. Pugliese JMP, Mehdi A. Fini, Andrea Olschewski, Karim C. El Kasmi,and Kurt R. Stenmark. The role of inflammation in hypoxic pulmonary hypertension: from cellular mechanisms to clinical phenotypes. Am J Physiol Lung Cell Mol Physiol. 2015;308:L229-L52.

2. Nazzareno Galiè MH, Jean-Luc Vachiery, Simon Gibbs, Irene Lang, AdamTorbicki, Gérald Simonneau, et al. 2015 ESC/ERS Guidelines for the diagnosis and treatment of pulmonary hypertension. The European respiratory journal. 2015;46:879-82. 3. Ruifeng Zhang, Liuhong Shi, Lin Zhou, Gensheng Zhang, Xiaohong Wu, Fangchun Shao, et al. Transgelin as a therapeutic target to prevent hypoxic pulmonary hypertension. Am J Physiol Lung Cell Mol Physiol. 2014;306:L574-L83.

4. Ball MK, Waypa GB, Mungai PT, Nielsen JM, Czech L, Dudley VJ, et al. Regulation of hypoxia-induced pulmonary hypertension by vascular smooth muscle hypoxiainducible factor-1alpha. American journal of respiratory and critical care medicine. 2014;189(3):314-24. 5. Meng X, Li X, Zhang P, Wang J, Zhou Y, Chen M. Circular RNA: an emerging key player in RNA world. Briefings in bioinformatics. 2017;18(4):547-57.

6. Salzman J. Circular RNA Expression: Its Potential Regulation and Function. Trends in genetics : TIG. 2016;32(5):309-16. 8.

8. Pamudurti NR, Bartok O, Jens $M$, Ashwal-Fluss R, Stottmeister $C$, Ruhe $L$, et al. Translation of CircRNAs. Molecular cell. 2017;66(1):1-13. RNAs driven by N(6)-methyladenosine. Cell research. 2017;27(5):626-41. and Characterization of Hypoxia-Regulated Endothelial Circular RNA. Circulation research. 2015;117(10):884-90. endothelial cell proliferation and apoptosis by targeting the miR-186/HIF-1alpha axis. Biochemical and biophysical research communications. 2017;490(2):104-10. RNA expression in lung tissues from mice with hypoxiainduced pulmonary 
hypertension. International journal of molecular medicine. 2018;42(3):1353-66. 13. Chen K, Lu Z, Wang X, Fu Y, Luo GZ, Liu N, et al. High-resolution $N(6)$ methyladenosine ( $m(6) A)$ map using photo-crosslinking-assisted $m(6)$ A sequencing. Angewandte Chemie. 2015;54(5):1587-90.

14. Zhou C, Molinie B, Daneshvar K, Pondick JV, Wang J, Van Wittenberghe N, et al. Genome-Wide Maps of m6A circRNAs Identify Widespread and Cell-Type-Specific Methylation Patterns that Are Distinct from mRNAs. Cell reports. 2017;20(9):2262-76. 15. Zheng $Y$, Nie P, Peng D, He Z, Liu M, Xie Y, et al. m6AVar: a database of functional variants involved in m6A modification. Nucleic acids research. 2018;46(D1):D139-D45. 16. Xuan JJ, Sun WJ, Lin PH, Zhou KR, Liu S, Zheng LL, et al. RMBase v2.0: deciphering the map of RNA modifications from epitranscriptome sequencing data. Nucleic acids research. 2018;46(D1):D327-D34.

17. Wang $S$, Chai $P$, Jia $R$, Jia R. Novel insights on $m(6) A$ RNA methylation in tumorigenesis: a double-edged sword. Molecular cancer. 2018;17(1):101.

18. Dai D, Wang H, Zhu L, Jin H, Wang X. N6-methyladenosine links RNA metabolism to cancer progression. Cell Death Dis. 2018;9(2):124.

19. Meyer KD, Saletore $Y$, Zumbo $P$, Elemento $O$, Mason CE, Jaffrey SR. Comprehensive analysis of mRNA methylation reveals enrichment in 3' UTRs and near stop codons. Cell. 2012;149(7):1635-46.

20. Wang $X$, Huang J, Zou T, Yin P. Human m(6)A writers: Two subunits, 2 roles. RNA biology. 2017;14(3):300-4.

21. Deng $X$, Su R, Weng $H$, Huang $H$, Li Z, Chen J. RNA N(6)-methyladenosine modification in cancers: current status and perspectives. Cell research. 2018;28(5):507-17.

22. Wu B, Li L, Huang Y, Ma J, Min J. Readers, writers and erasers of N(6)-methylated adenosine modification. Current opinion in structural biology. 2017;47:67-76.

23. Liao S, Sun H, Xu C. YTH Domain: A Family of $N(6)$-methyladenosine (m(6)A) Readers. Genomics, proteomics \& bioinformatics. 2018;16(2):99-107.

24. Patil DP, Pickering BF, Jaffrey SR. Reading $m(6) A$ in the Transcriptome: $m(6) A-$ Binding Proteins. Trends in cell biology. 2018;28(2):113-27.

25. Subbarayalu Panneerdoss VKE, Pooja Yadav, Santosh Timilsina, Subapriya Rajamanickam, Suryavathi Viswanadhapalli, Nourhan Abdelfattah, et al. Cross-talk among writers, readers, and erasers of $\mathrm{m} 6 \mathrm{~A}$ regulates cancer growth and progression. SCIENCE ADVANCES. 2018;4:eaar8263.

26. Zhang $C$, Samanta $D$, Lu H, Bullen JW, Zhang $H$, Chen I, et al. Hypoxia induces the breast cancer stem cell phenotype by HIF-dependent and ALKBH5-mediated m(6)Ademethylation of NANOG mRNA. Proc Natl Acad Sci 2016;113(14):E2047-56.

27. Rowan SC, Keane MP, Gaine S, McLoughlin P. Hypoxic pulmonary hypertension in chronic lung diseases: novel vasoconstrictor pathways. The Lancet Respiratory Medicine. 2016;4(3):225-36.

28. Chan JJ, Tay Y. Noncoding RNA:RNA Regulatory Networks in Cancer. International journal of molecular sciences. 2018;19(5):1310.

29. Baarsma HA, Konigshoff M. 'WNT-er is coming': WNT signalling in chronic lung diseases. Thorax. 2017;72(8):746-59. 
30. de Jesus Perez V, Yuan K, Alastalo TP, Spiekerkoetter E, Rabinovitch M. Targeting the Wnt signaling pathways in pulmonary arterial hypertension. Drug discovery today. 2014;19(8):1270-6.

31. Savai R, Al-Tamari HM, Sedding D, Kojonazarov B, Muecke C, Teske R, et al. Proproliferative and inflammatory signaling converge on FoxO1 transcription factor in pulmonary hypertension. Nature medicine. 2014;20(11):1289-300.

32. Su $H, X u X$, Yan C, Shi Y, Hu Y, Dong L, et al. LncRNA H19 promotes the proliferation of pulmonary artery smooth muscle cells through AT1R via sponging let-7b in monocrotaline-induced pulmonary arterial hypertension. Respir Res. 2018;19(1):254. 33. Caruso P, MacLean MR, Khanin R, McClure J, Soon E, Southgate M, et al. Dynamic changes in lung microRNA profiles during the development of pulmonary hypertension due to chronic hypoxia and monocrotaline. Arteriosclerosis, thrombosis, and vascular biology. 2010;30(4):716-23.

34. Zhong X, Yu J, Frazier K, Weng X, Li Y, Cham CM, et al. Circadian Clock Regulation of Hepatic Lipid Metabolism by Modulation of m(6)A mRNA Methylation. Cell reports. 2018;25(7):1816-28.

35. Dorn LE, Lasman L, Chen J, Xu X, Hund TJ, Medvedovic M, et al. The N(6)Methyladenosine mRNA Methylase METTL3 Controls Cardiac Homeostasis and Hypertrophy. Circulation. 2019;139(4):533-45.

36. Dandan Yang, Jing Qiao, GuiyingWang, Yuanyuan Lan, Guoping Li, Xudong Guo, et al. N6-Methyladenosine modification of lincRNA 1281 is critically required for mESC Nucleic Acids Res. 2018; 46(8): 3906-3920.

37. Nate J. Fry BAL, Olga R. Ilkayeva, Christopher L. Holley, and Kyle D. Mansfield. N6methyladenosine is required for the hypoxic stabilization of specific mRNAs. Rna. 2017;23(9):1444-55.

38. Song $H$, Feng $X$, Zhang $H$, Luo $Y$, Huang $J$, Lin $M$, et al. METTL3 and ALKBH5 oppositely regulate $\mathrm{m}(6) \mathrm{A}$ modification of TFEB mRNA, which dictates the fate of hypoxia/reoxygenation-treated cardiomyocytes. Autophagy. 2019:1-19.

39. Luo GZ, MacQueen A, Zheng G, Duan H, Dore LC, Lu Z, et al. Unique features of the m6A methylome in Arabidopsis thaliana. Nature communications. 2014;5:5630.

40. Chen L, Zhang S, Wu J, Cui J, Zhong L, Zeng L, et al. circRNA_100290 plays a role in oral cancer by functioning as a sponge of the miR-29 family. Oncogene. 2017;36(32):4551-61.

41. Salmena L, Poliseno L, Tay Y, Kats L, Pandolfi PP. A ceRNA hypothesis: the Rosetta Stone of a hidden RNA language? Cell. 2011;146(3):353-8.

42. James D. West EDA, Christa Gaskill, Shennea Marriott, Rubin Baskir,Ganna Bilousova, Jyh-Chang Jean, et al. Identification of a common Wnt-associated genetic signature across multiple cell types in pulmonary arterial hypertension. Am J Physiol Cell Physiol. 2014;307:C415-C30.

43. Awad H, Nolette $\mathrm{N}$, Hinton M, Dakshinamurti S. AMPK and FoxO1 regulate catalase expression in hypoxic pulmonary arterial smooth muscle. Pediatric pulmonology. 2014;49(9):885-97.

44. Cowburn AS, Crosby A, Macias D, Branco C, Colaco RD, Southwood M, et al. HIF2alpha-arginase axis is essential for the development of pulmonary hypertension. 
579 Proceedings of the National Academy of Sciences of the United States of America.

580 2016;113(31):8801-6.

581 45. Xu X, Hu H, Wang X, Ye W, Su H, Hu Y, et al. Involvement of CapG in proliferation 582 and apoptosis of pulmonary arterial smooth muscle cells and in hypoxia-induced 583 pulmonary hypertension rat model. Experimental lung research. 2016;42(3):142-53.

584 46. Yamazato Y, Ferreira AJ, Hong KH, Sriramula S, Francis J, Yamazato M, et al. 585 Prevention of pulmonary hypertension by Angiotensin-converting enzyme 2 gene 586 transfer. Hypertension. 2009;54(2):365-71.

587 47. Xiao R, Su Y, Feng T, Sun M, Liu B, Zhang J, et al. Monocrotaline Induces Endothelial 588 Injury and Pulmonary Hypertension by Targeting the Extracellular Calcium-Sensing 589 Receptor. Journal of the American Heart Association. 2017;6(4):e004865.

590 48. Xin Yun, Haiyang Jiang, Ning Lai, Jian Wang, and Larissa A. Aquaporin 1-mediated 591 changes in pulmonary arterial smooth muscle cell migration and proliferation involve 592 B-catenin. Am J Physiol Lung Cell Mol Physiol. 2017;313:L889-L98.

593 49. Zhang HY, Liu Y, Yan LX, Du W, Zhang XD, Zhang M, et al. Bone morphogenetic 594 protein-7 inhibits endothelial-mesenchymal transition in pulmonary artery 595 endothelial cell under hypoxia. Journal of Cellular Physiology. 2018;233(5):4077-90.

596 50. Omura J, Satoh K, Kikuchi N, Satoh T, Kurosawa R, Nogi M, et al. Protective Roles 597 of Endothelial AMP-Activated Protein Kinase Against Hypoxia-Induced Pulmonary 598 Hypertension in Mice. Circulation research. 2016;119(2):197-209.

599 51. Thomas B. Hansen MTV, Christian K. Damgaard and Jørgen Kjems. Comparison of 600 circular RNA prediction tools. Nucleic acids research. 2015;44(6):e58.

601 52. Tian L, Greenberg SA, Kong SW, Altschuler J, Kohane IS, Park PJ. Discovering 602 statistically significant pathways in expression profiling studies. Proceedings of the 603 National Academy of Sciences of the United States of America. 2005;102(38):135446049.

605

606

607

608

609

610

611

612

613

614

615

616 


\section{Figure legends}

Fig $1 . m^{6} A$ level of circRNAs in $H P H$ rats and the number of $m^{6} A$ peak in circRNAs

627

Rats were maintained in a normobaric normoxic $\left(\mathrm{FiO}_{2} 21 \%\right)$ or hypoxic $\left(\mathrm{FiO}_{2} 10 \%\right)$ chamber for 3 weeks, then RVSP was detected (A, B). (C) The ratio of RV/ (LV+S). (D) H\&E staining and immunohistochemical staining of $\alpha$-SMA were performed in the lung sections. Representative images of pulmonary small arteries. Scale bar $=50 \mu \mathrm{m}$. Quantification of wall thickness (E) and vessel muscularization (F). (G) Heatmap depicting hierarchical clustering of altered $\mathrm{m}^{6} \mathrm{~A}$ circRNAs in lungs of normal $(\mathrm{N})$ and hypoxic pulmonary hypertension (HPH) rats. Red represents higher expression and yellow represents lower expression level. (H) Box-plot for $\mathrm{m}^{6} \mathrm{~A}$ peaks enrichment in circRNAs in N and HPH. (I) The distribution of the number of circRNAs (y axis) was plotted based on the number of $\mathrm{m}^{6} \mathrm{~A}$ peaks in circRNAs ( $\mathrm{x}$ axis) in $\mathrm{N}$ and HPH. Values are presented as means $\pm \mathrm{SD}$ ( $\mathrm{n}=6$ in each group). Only vessels with diameter between 30 and $90 \mu \mathrm{m}$ were analyzed. NM, nonmuscularized vessels; PM, partially muscularized vessels; FM, fully muscularized vessels. ${ }^{* *} 0.001 \leq \mathrm{p} \leq 0.009$ (different from $\mathrm{N}) ; * * * \mathrm{p}<0.001$ (different from $\mathrm{N})$.

\section{Fig 2. The genomic origins of $m^{6} A$ circRNAs}

The distribution of genomic origins of total circRNAs (input, left), $\mathrm{m}^{6} \mathrm{~A}$ circRNAs (eluate, center), and non- $\mathrm{m}^{6} \mathrm{~A}$ circRNAs (supernatant, right) in $\mathrm{N}(\mathrm{A})$ and $\mathrm{HPH}(\mathrm{B})$. The percentage of circRNAs ( $\mathrm{y}$ axis) was calculated according to the number of exons ( $\mathrm{x}$ axis) spanned by each circRNA for the input circRNAs (left), $\mathrm{m}^{6} \mathrm{~A}$-circRNAs (red, right) 
and non- $\mathrm{m}^{6} \mathrm{~A}$ circRNAs (blue, right) in $\mathrm{N}(\mathrm{C})$ and $\mathrm{HPH}$ (D). Up to seven exons are shown.

\section{Fig 3. The distribution and functional analysis for host genes of circRNAs with} differentially expressed (DE) $\mathrm{m}^{6} \mathrm{~A}$ peaks
(A) DE $m^{6} \mathrm{~A}$ circRNAs length.
(B) The chromosomes origins for host genes of $\mathrm{DE} \mathrm{m}^{6} \mathrm{~A}$ circRNAs. GO enrichment and KEGG signaling pathway analysis for host genes of upregulated (C) and downregulated (D) $\mathrm{m}^{6} \mathrm{~A}$ circRNAs. GO enrichment analysis include biological process (BP) analysis, cellular component (CC) analysis, and molecular function (MF) analysis. P values are calculated by DAVID tool.

Fig 4. The relationship of $\mathbf{m}^{6} \mathrm{~A}$ level of circRNAs and circRNAs abundance in hypoxia

(A) Venn diagram depicting the overlap of $\mathrm{m}^{6} \mathrm{~A}$ circRNAs between $\mathrm{N}$ and $\mathrm{HPH}$. (B)

Two-dimensional histograms comparing the expression of $\mathrm{m}^{6} \mathrm{~A}$ circRNAs in lungs of $\mathrm{N}$ and HPH rats. It showed that $\mathrm{m}^{6} \mathrm{~A}$ circRNAs levels for all shared circRNAs in both groups. CircRNAs counts were indicated on the scale to the right. (C) Cumulative distribution of circRNAs expression between $\mathrm{N}$ and $\mathrm{HPH}$ for $\mathrm{m}^{6} \mathrm{~A}$ circRNAs (red) and non- $\mathrm{m}^{6} \mathrm{~A}$ circRNAs (blue). $\mathrm{P}$ value was calculated using two-sided Wilcoxon-MannWhiteney test.

\section{Fig 5. Construction of a circRNA-miRNA-mRNA co-expression network in HPH} (A) Comparison of the relationship between $\mathrm{m}^{6} \mathrm{~A}$ level and expression of circRNAs between $\mathrm{N}$ and $\mathrm{HPH}$. The fold-change $\geq 2.0$ was considered to be significant, which was the abundance of $\mathrm{m}^{6} \mathrm{~A}$ peaks of $\mathrm{HPH}$ relative to N. Red dots represents circRNAs with upregulated $\mathrm{m}^{6} \mathrm{~A}$ level and blue dots represents circRNAs with downregulated $\mathrm{m}^{6} \mathrm{~A}$ level. IP/Input referred to the abundance of $\mathrm{m}^{6} \mathrm{~A}$ peak in circRNAs detected in MeRIPSeq (IP) normalized to that detected in input. (B and C) GO enrichment analysis includes BP analysis, CC analysis, and MF analysis. P values are calculated by DAVID tool. (D and E) KEGG signaling pathway analysis for the downstream mRNAs which 
677 was predicted to be ceRNA of DE cirRNAs. Methy. down \& exp. down represents 678 downregulated cirRNAs with decreased $\mathrm{m}^{6} \mathrm{~A}$ level. Methy. up \& exp. up represents upregulated cirRNAs with increased $\mathrm{m}^{6} \mathrm{~A}$ level. ( $\mathrm{F}$ and $\mathrm{G}$ ) CeRNA analysis for DE circRNAs. Network map of circRNA-miRNA-mRNA interactions. Green V type node: miRNA; yellow circular node: DE circRNAs; blue hexagon node: target genes of miRNAs; red hexagon node: PH-related genes.

Fig 6. The expression profiling of $\mathrm{m}^{6} \mathrm{~A}$ circXpo6 and $\mathrm{m}^{6} \mathrm{~A}$ circTmtc3 in PASMCs and PAECs in hypoxia

(A) Box-plot for $\mathrm{m}^{6} \mathrm{~A}$ peaks enrichment in circRNAs in vitro. Pulmonary arterial smooth muscle cells (PASMCs) and pulmonary artery endothelial cells (PAECs) were exposed to $21 \% \mathrm{O}_{2}$ and $1 \% \mathrm{O}_{2}$ for $48 \mathrm{~h}$. Total RNA was extracted and treated by RNase R. $\mathrm{m}^{6} \mathrm{~A}$ levels were determined as a percentage of total circRNAs. (B) Schematic representation of exons of the Xpo6 and Tmtc3 circularization forming circXpo6 and circTmtc3 (black arrow). (C) RT-PCR validation of circXpo6 and circTmtc3 in PASMCs and PAECs exposed to $21 \% \mathrm{O}_{2}$. Divergent primers amplified circRNAs in cDNA, but not in genomic DNA (gDNA). The size of the DNA marker is indicated on the left of the gel. (D and E) RT-PCR and qRT-PCR was performed after $\mathrm{m}^{6} \mathrm{~A}$ RIP in PASMCs and PAECs exposed to $21 \%(\mathrm{~N})$ and $1 \% \mathrm{O}_{2}(\mathrm{H})$ for $48 \mathrm{~h}$. Input was used as a control (D). IgG was used as a negative control (E). Values are presented as means \pm SD. ${ }^{*} \mathrm{p} \leq 0.05$ (different from $21 \% \mathrm{O}_{2}$ or the $\mathrm{N}$-anti-m ${ }^{6} \mathrm{~A}$ ); $* * 0.001 \leq \mathrm{p} \leq 0.009$ (different from the $\mathrm{N}$-anti-m ${ }^{6} \mathrm{~A}$ ).

\section{Supporting information}

S1 Fig. KEGG pathway analysis for Wnt and FoxO signaling pathway in methy. up \& exp. up group.

S2 Fig. KEGG pathway analysis for Wnt and FoxO signaling pathway in methy. 
707 S1 Table. Differentially expressed $\mathbf{m}^{6} \mathbf{A}$ abundance in circRNAs.

708

709 S2 Table. Differentially expressed $\mathbf{m}^{\mathbf{6}} \mathbf{A}$ abundance linked with differentially

710 expressed circRNAs abundance.

711

712 


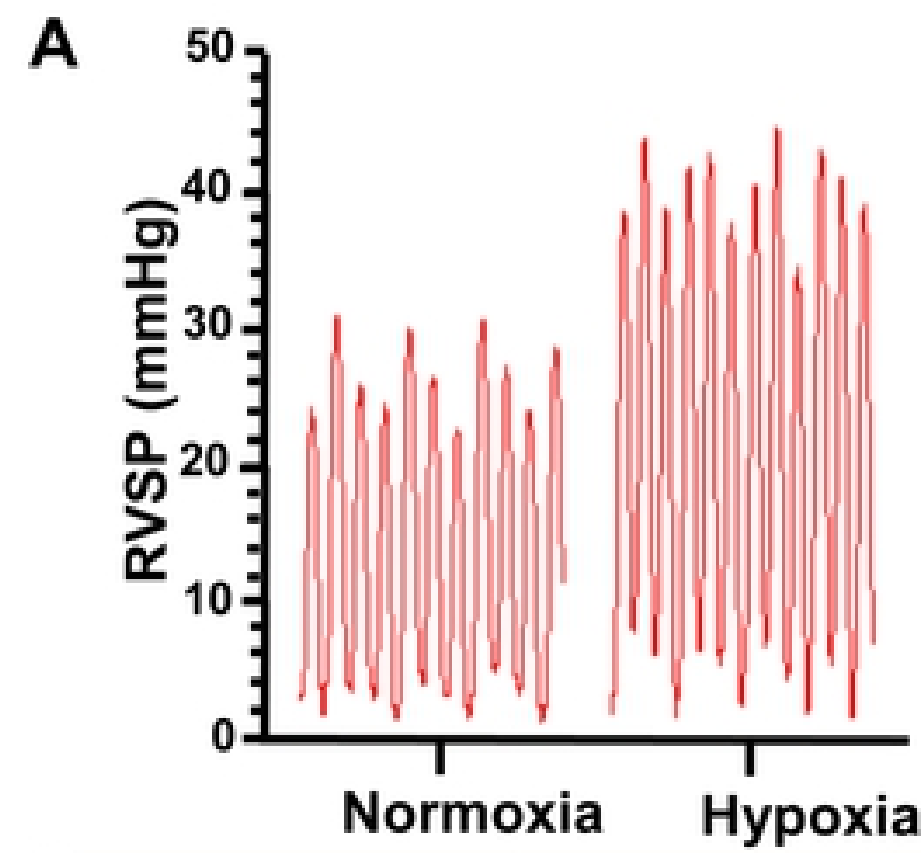

B

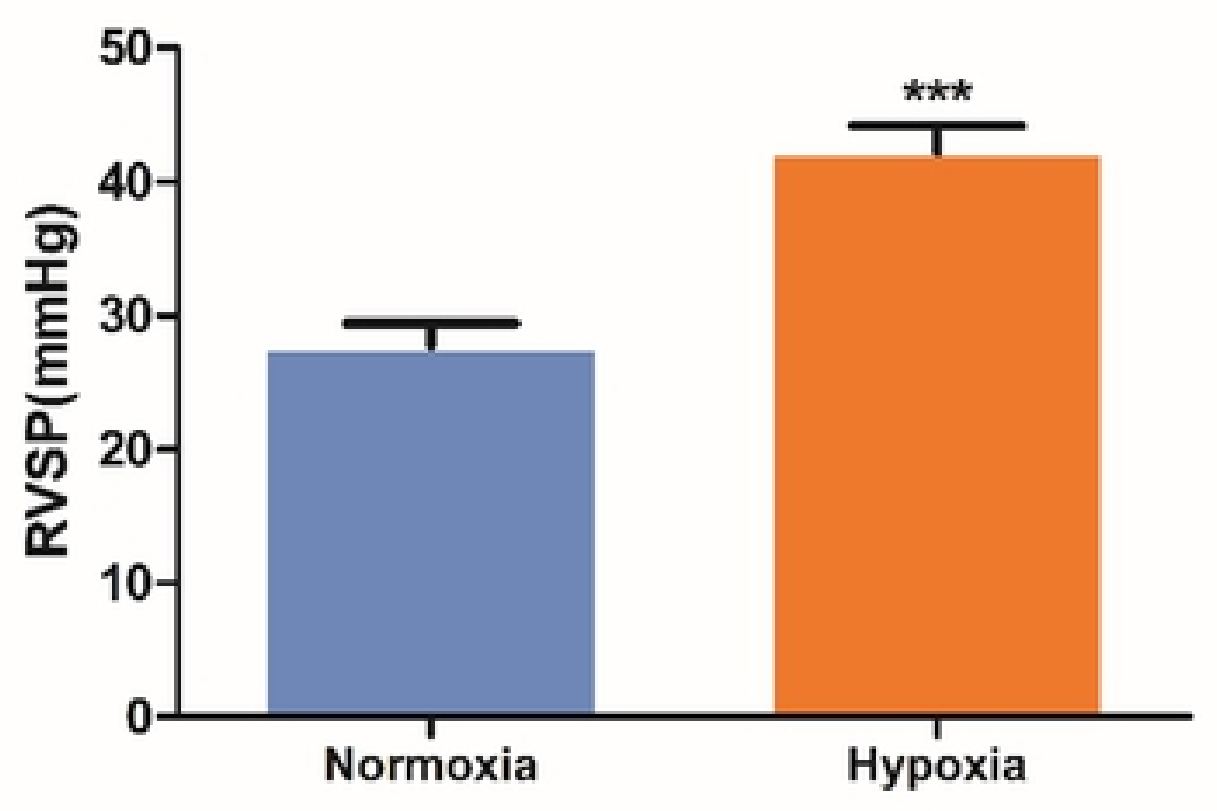

C bioRxiv preprint doi: https://doi.org/10.1101/625178; this version posted May 1, 2019. The copyright holder f

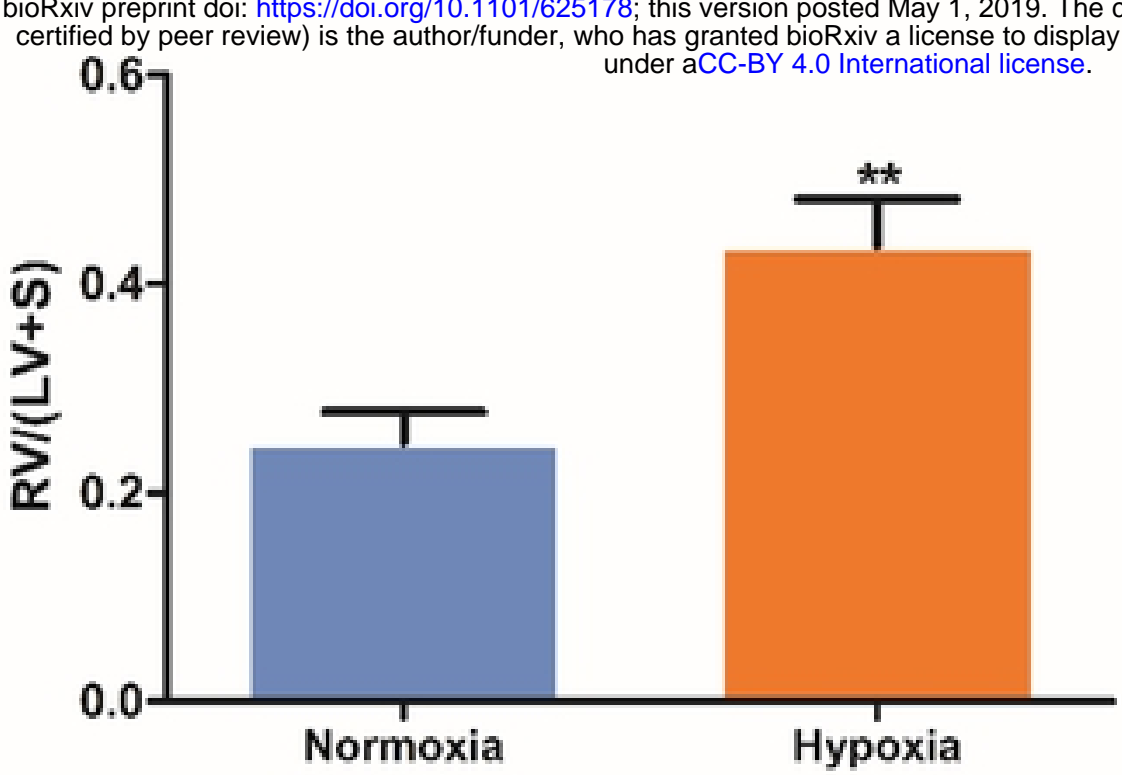

E

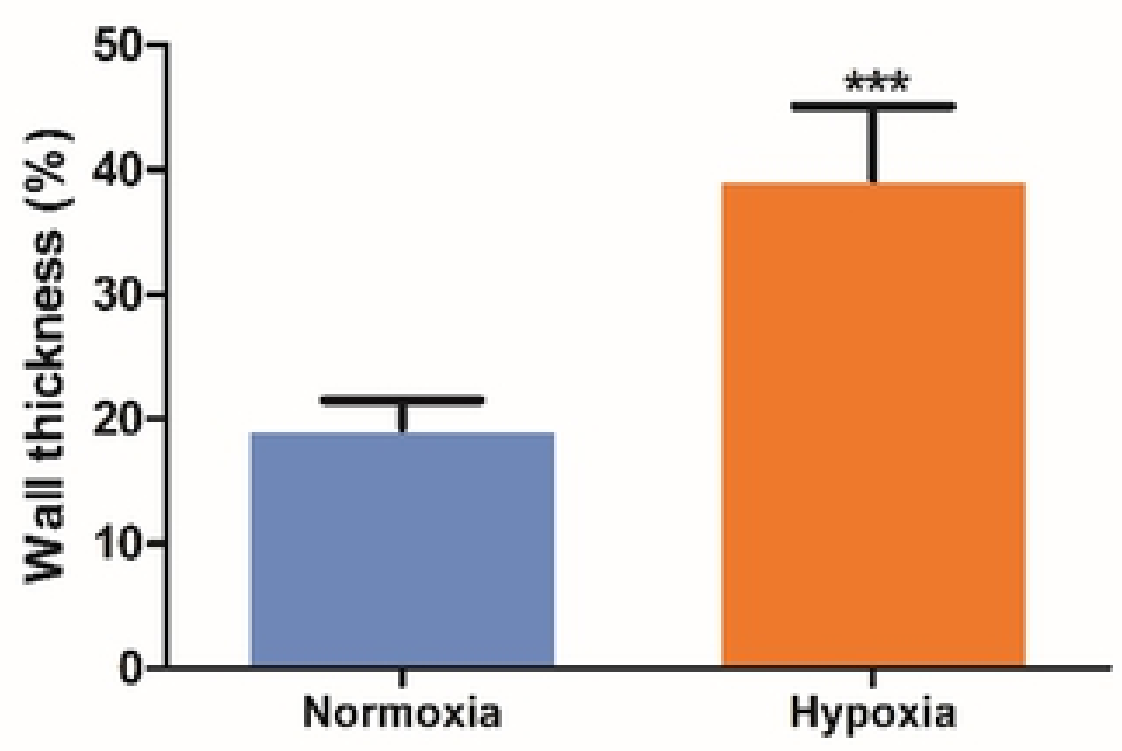

preprint (which was

preprint (which was made availat

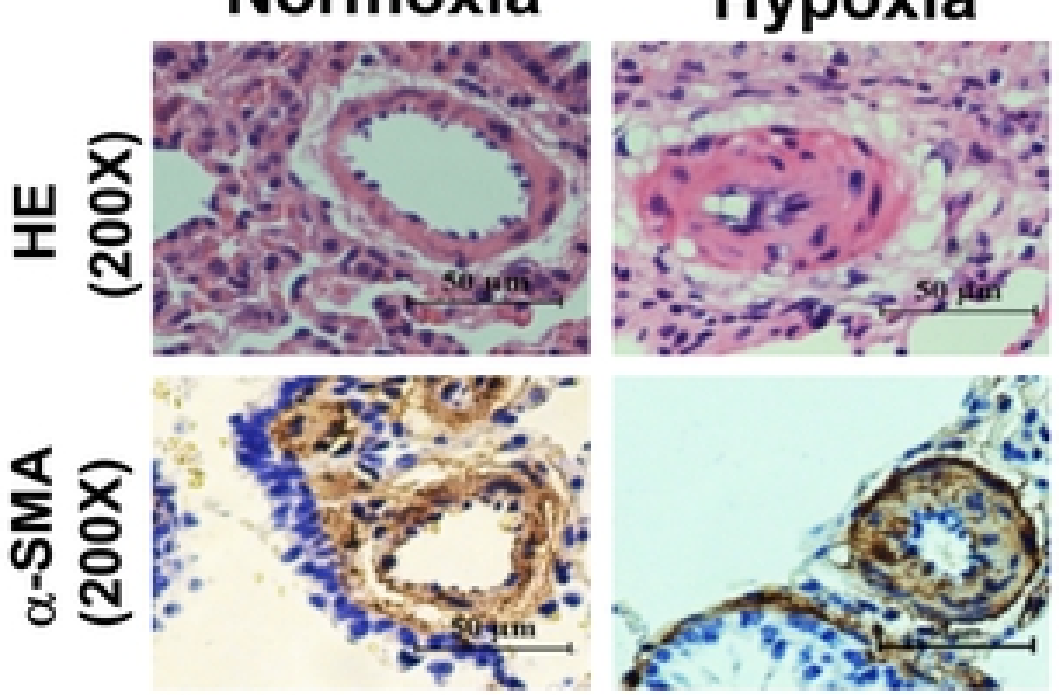

F

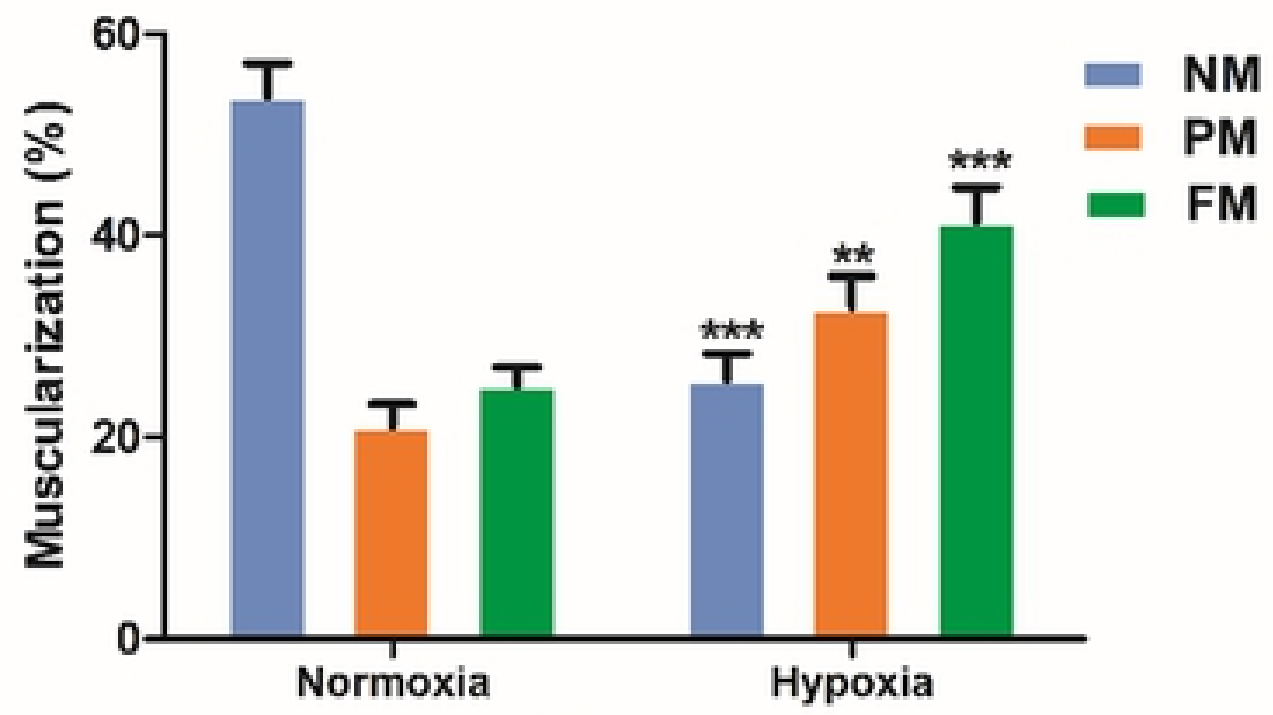

G

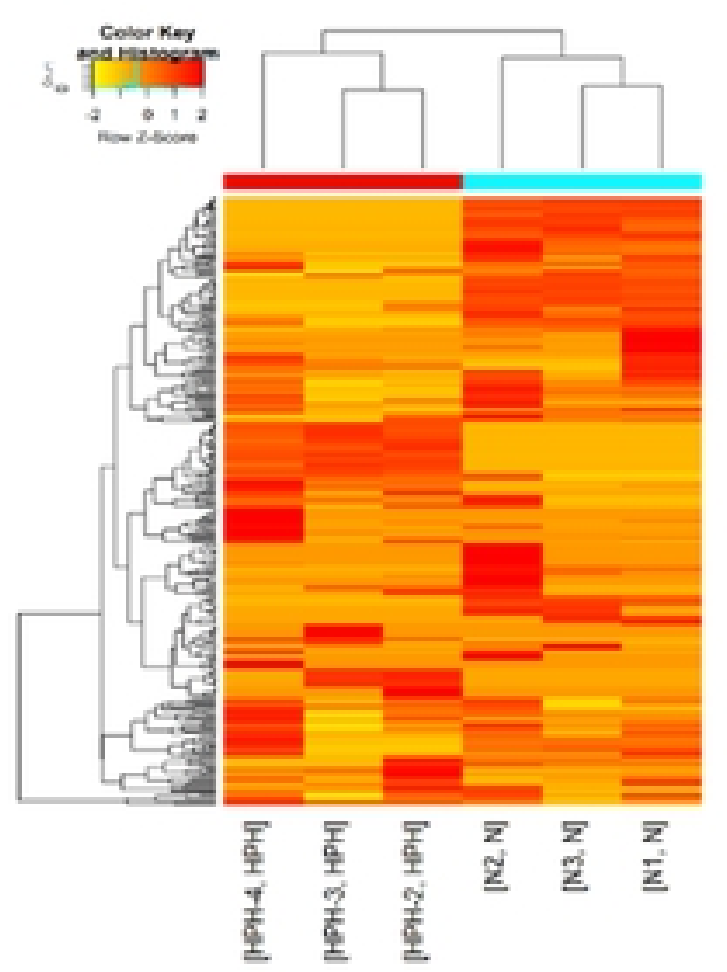

H
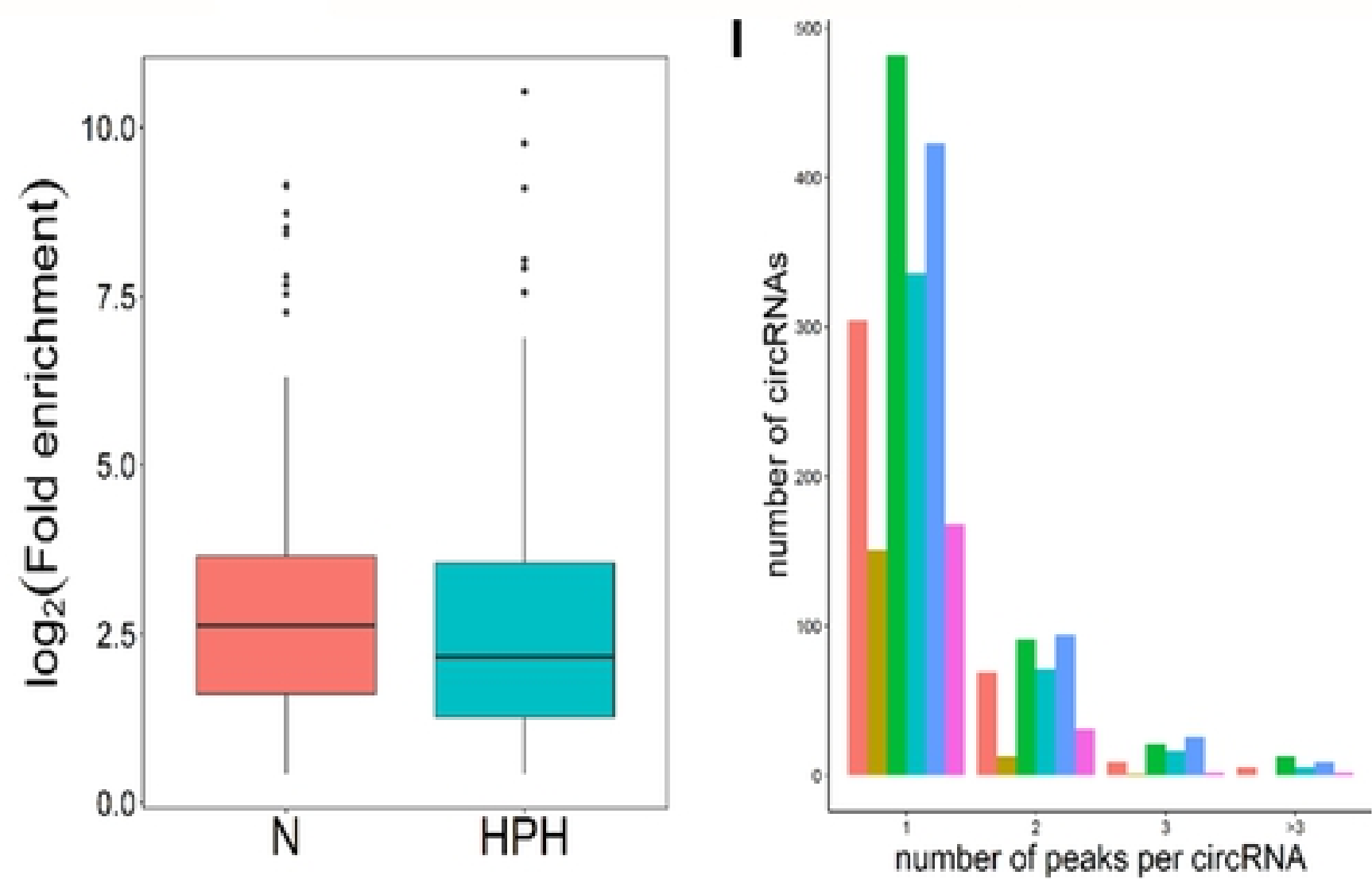

Figure 1 
A $\mathbf{N}$

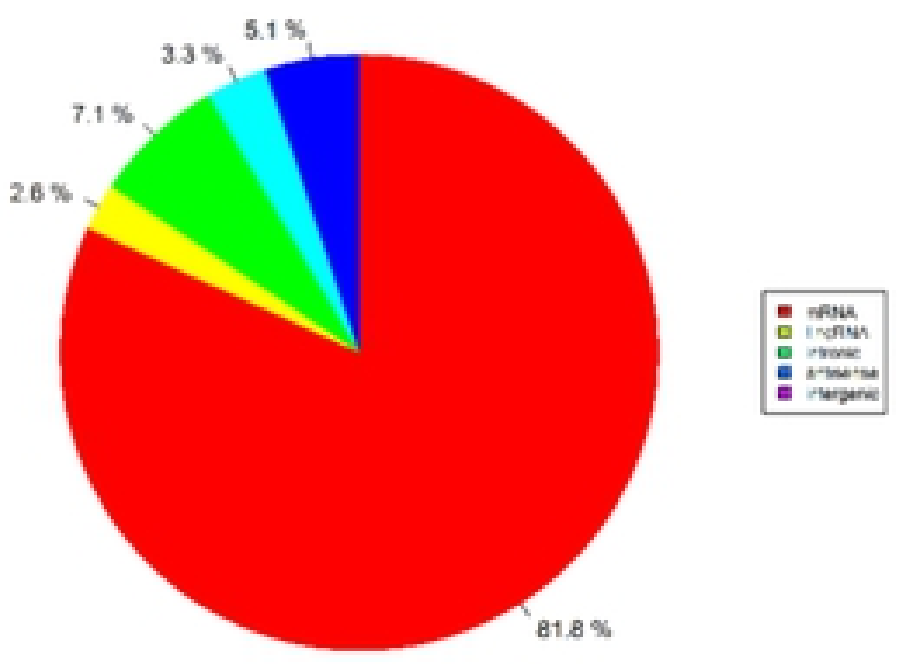

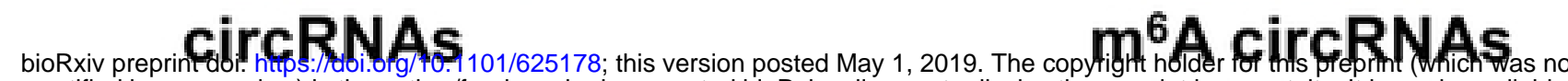

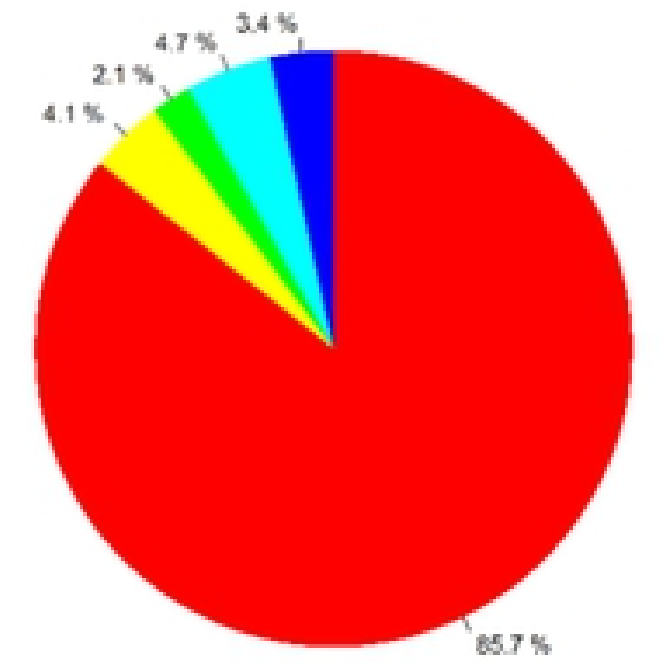
B HPH Heer review) is the author/funder, who has granted bioRxiv a license to displac $_{\text {under }} \mathrm{ACC}-\mathrm{BY} 4.0$ International license.

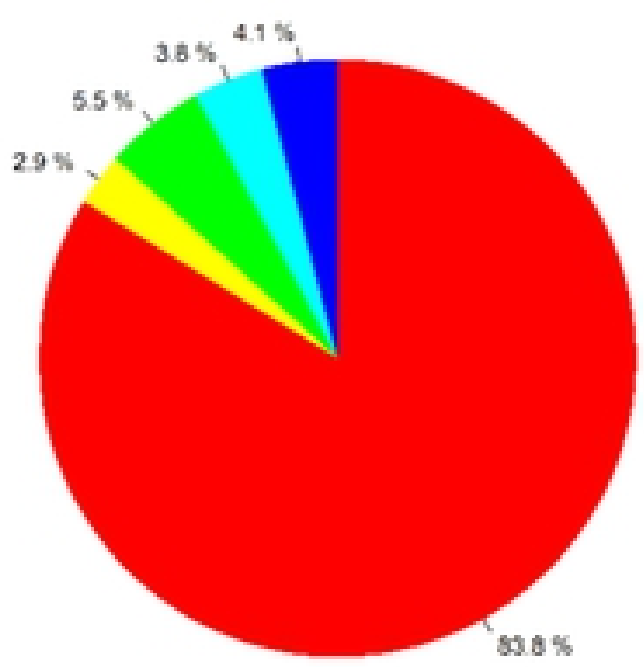

circRNAs

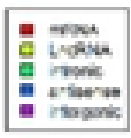

CircRNAs

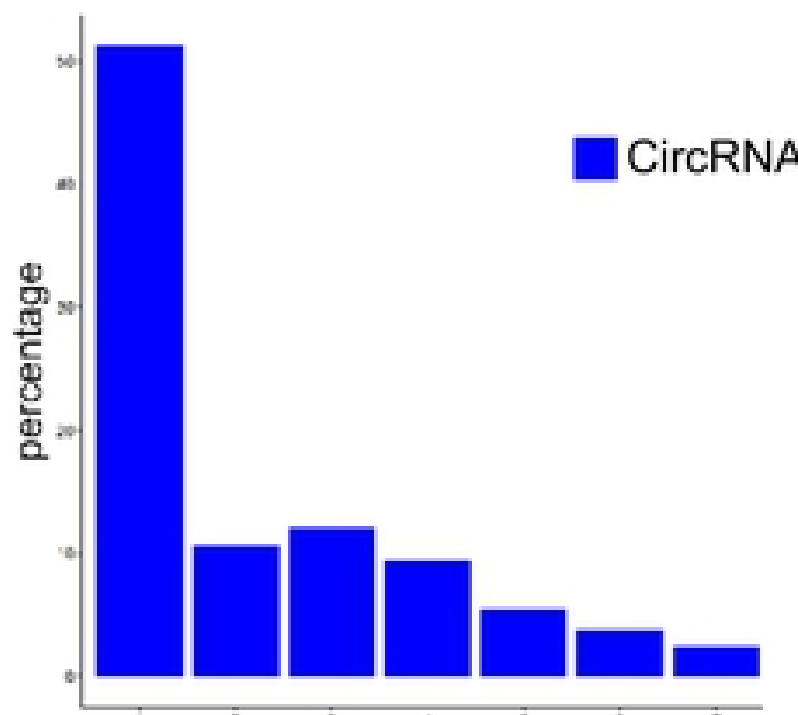

number of exons in circRNA

D HPH

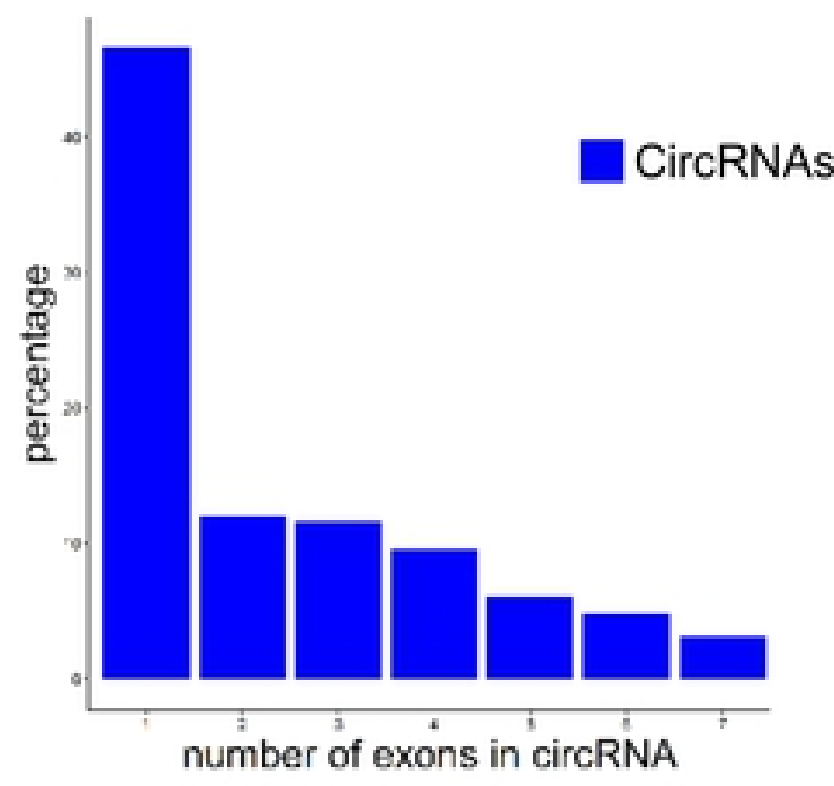

$\mathrm{m}^{6} \mathrm{~A}$ circRNAs

\section{:}

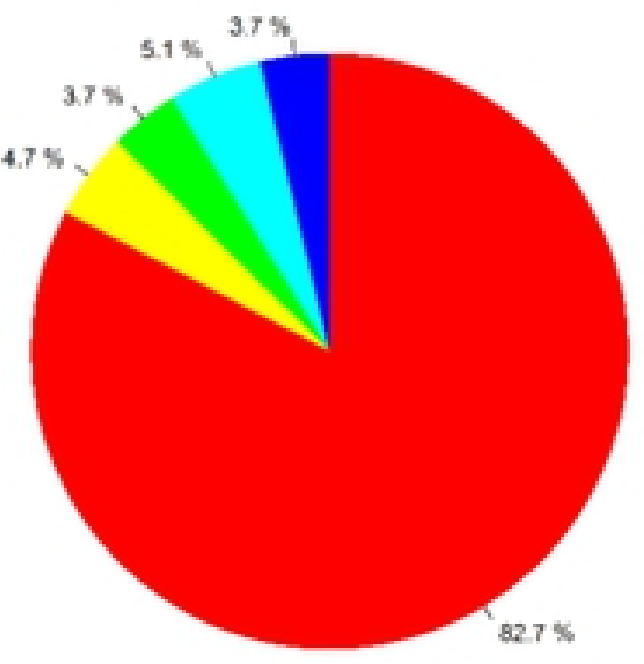

$\mathrm{m}^{6} \mathrm{~A}$ circRNAs

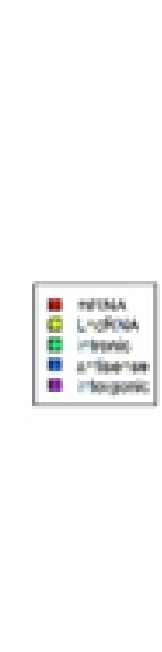

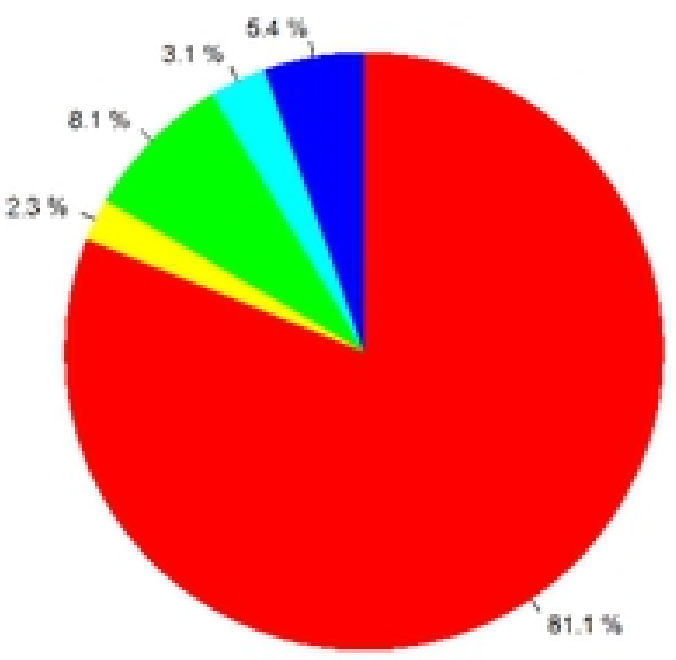

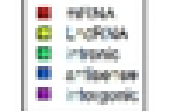
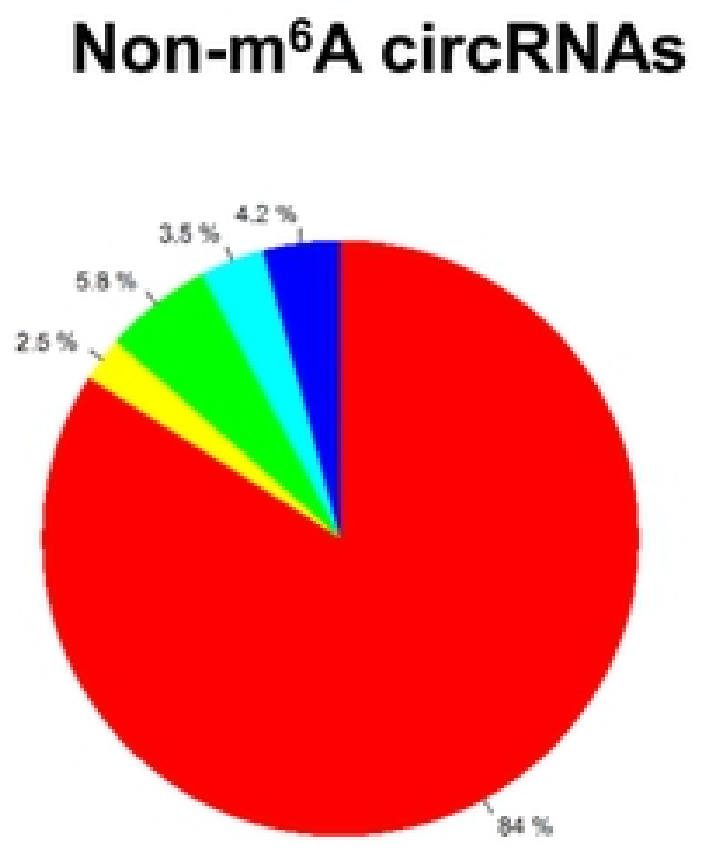

$=$

Non- ${ }^{6}{ }^{6}$ circRNAs
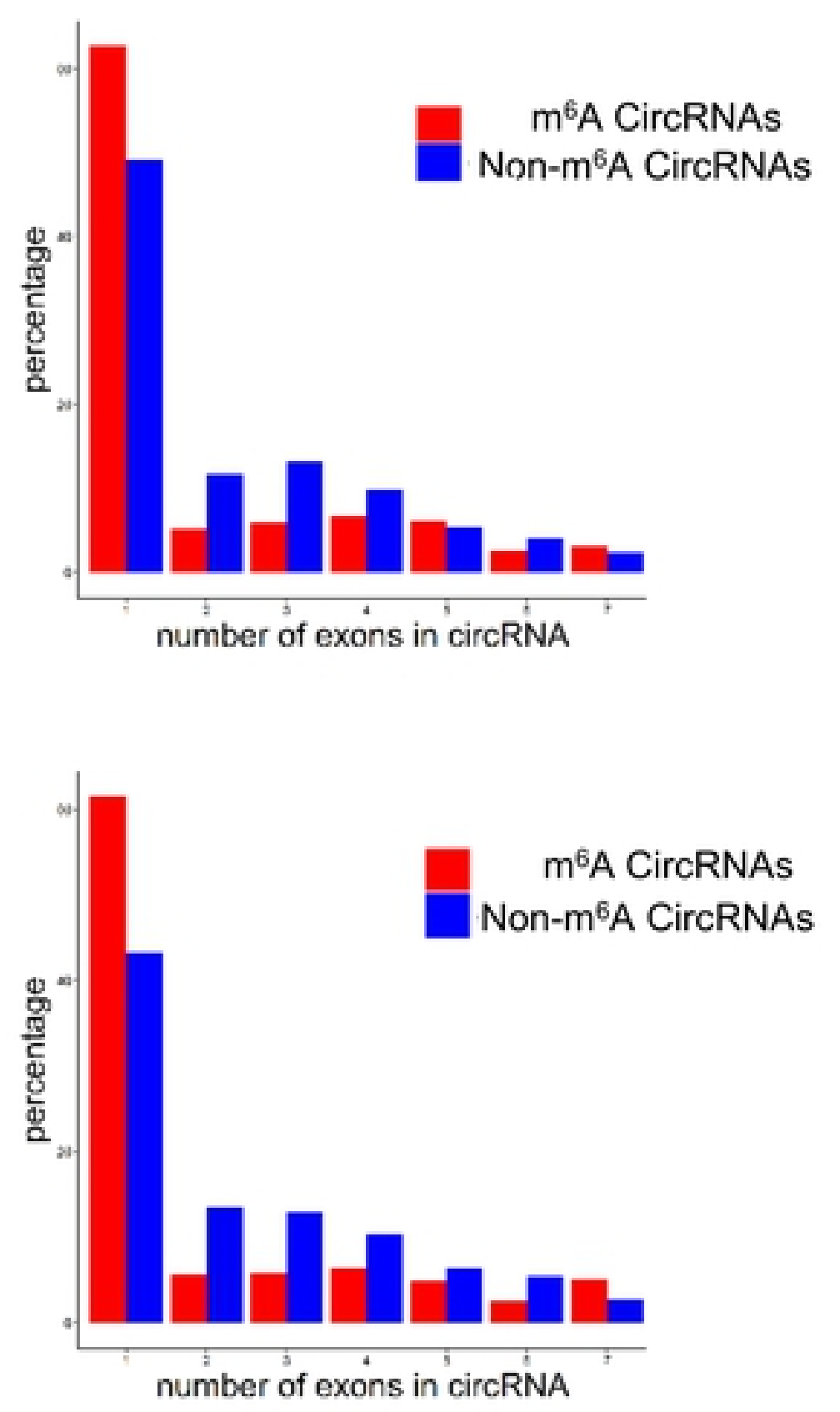

\section{Figure 2}


A Upregulated

CircRNA Length Distribution

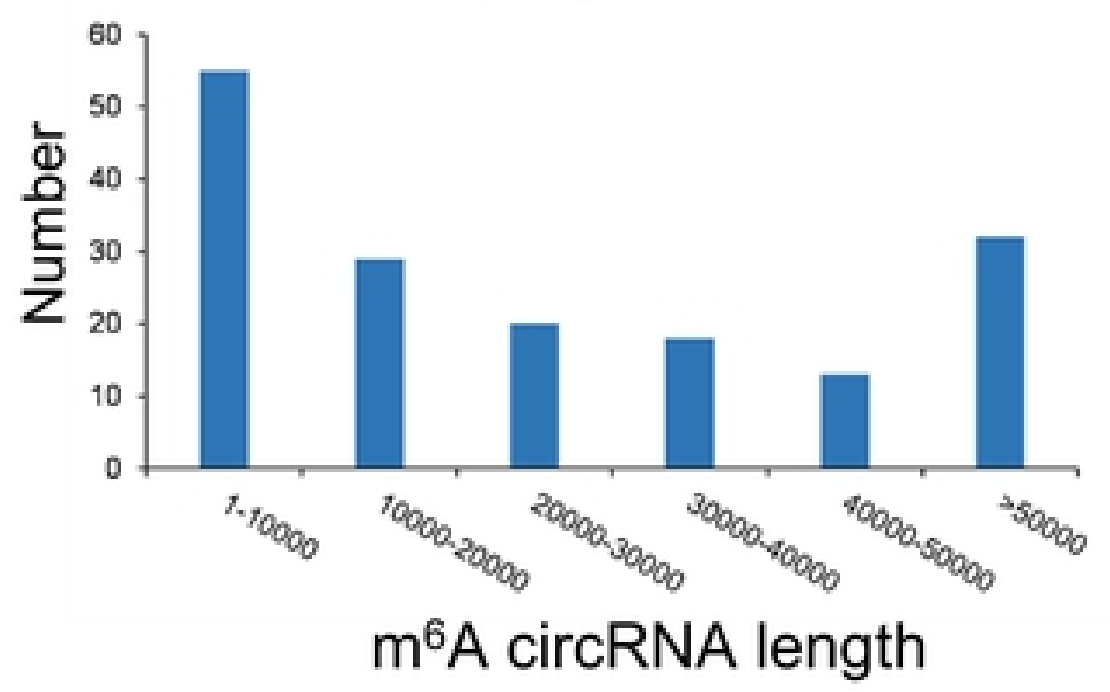

Downregulated

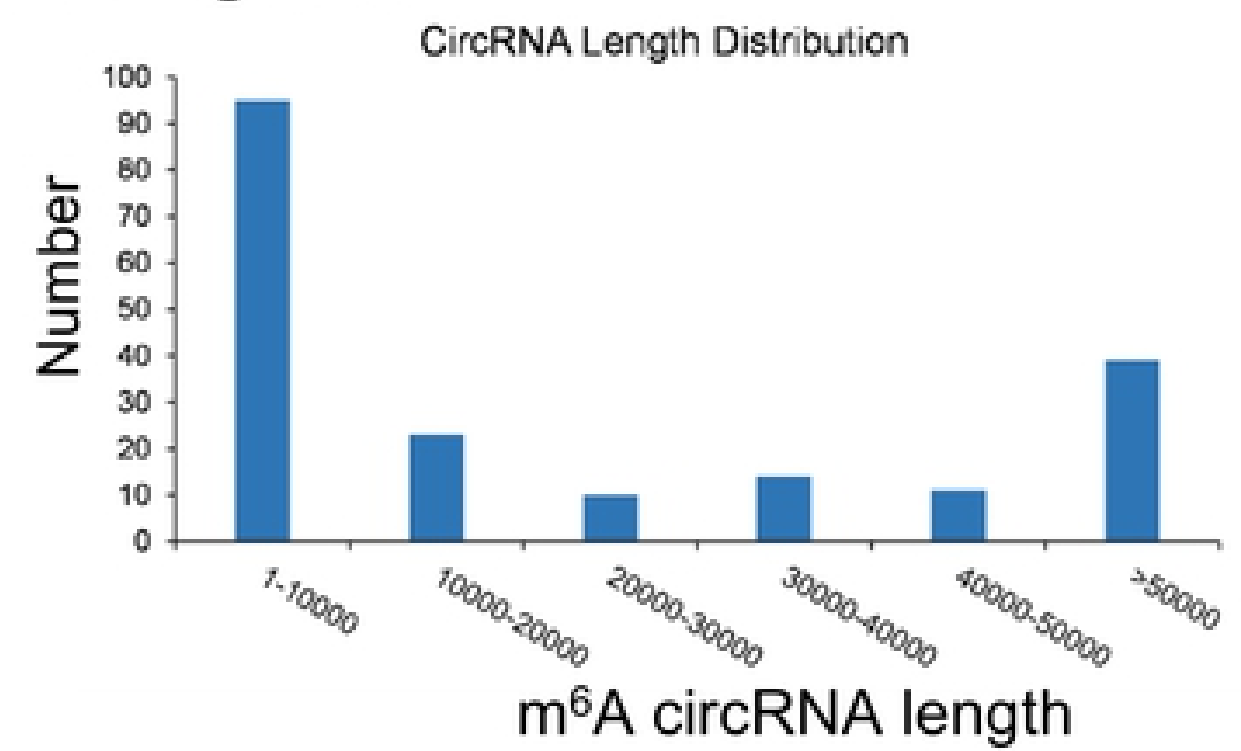

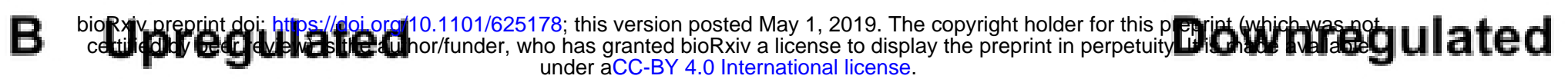

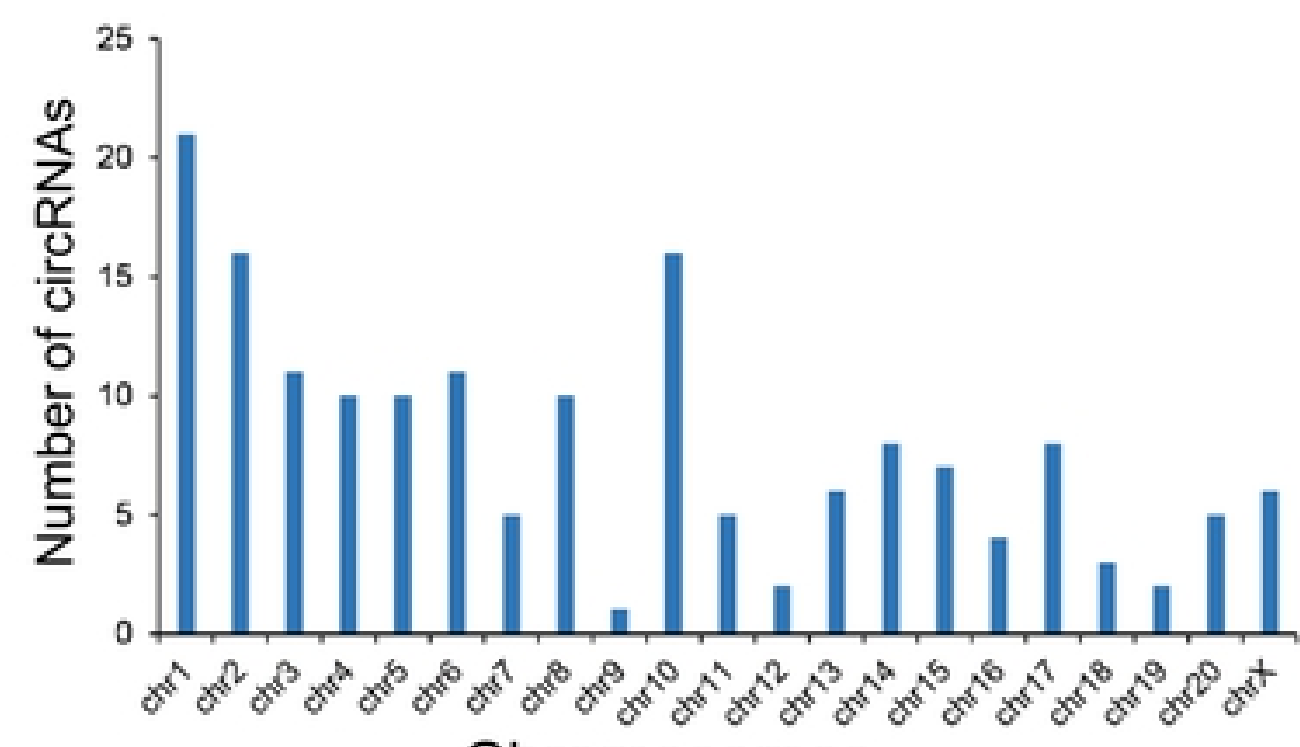

Chromosomes
- Log10 (Pvalue)

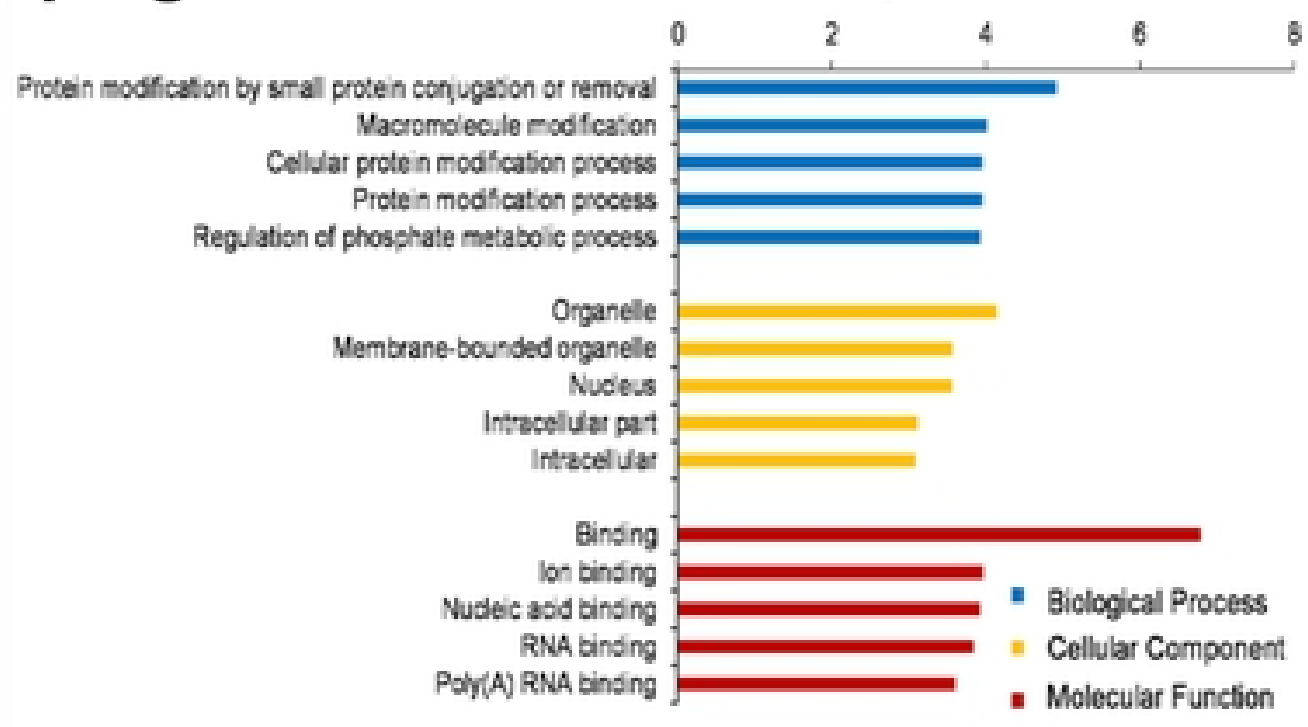

D Downregulated

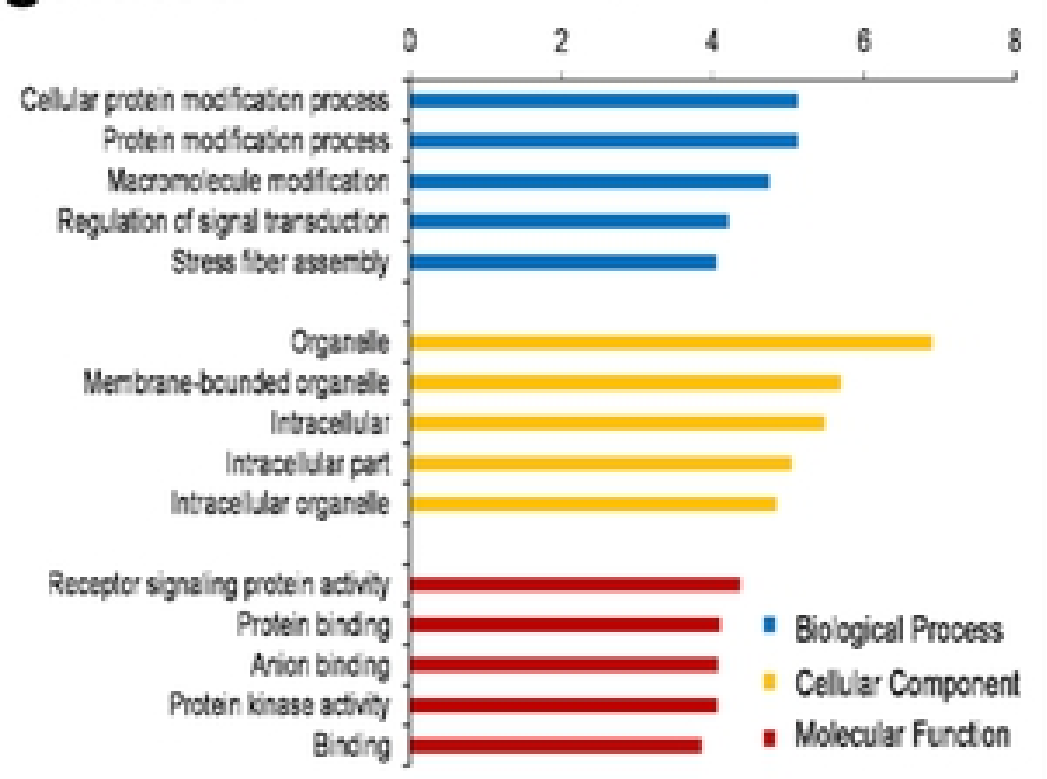

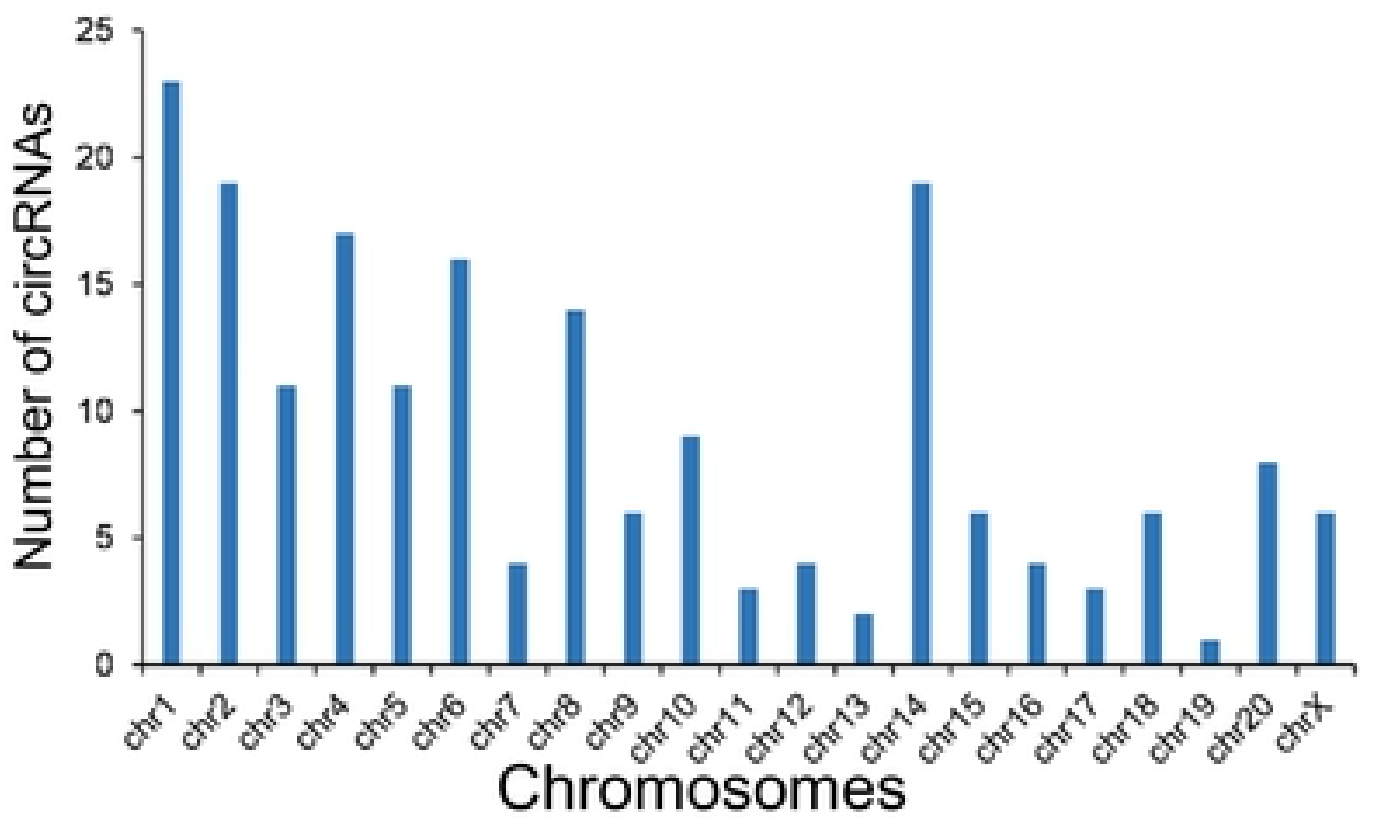

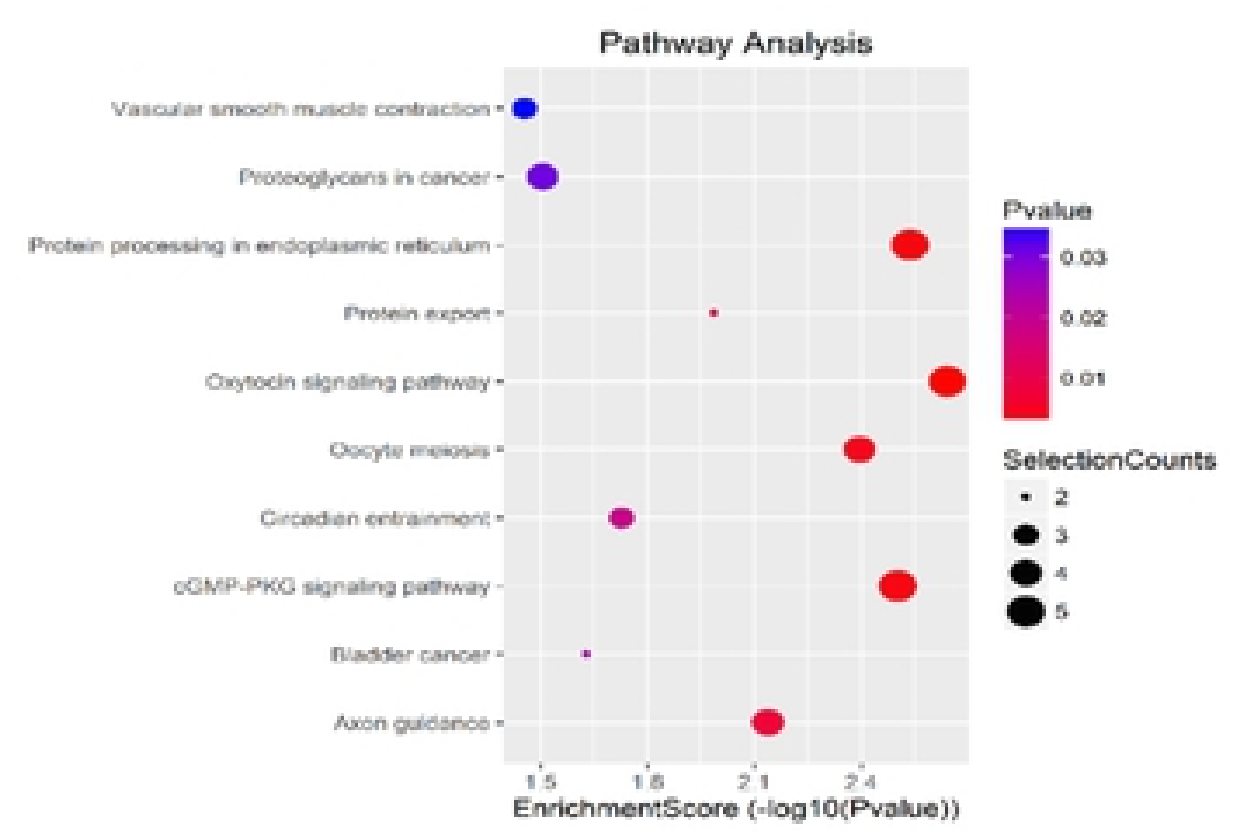

Pathway Analysis

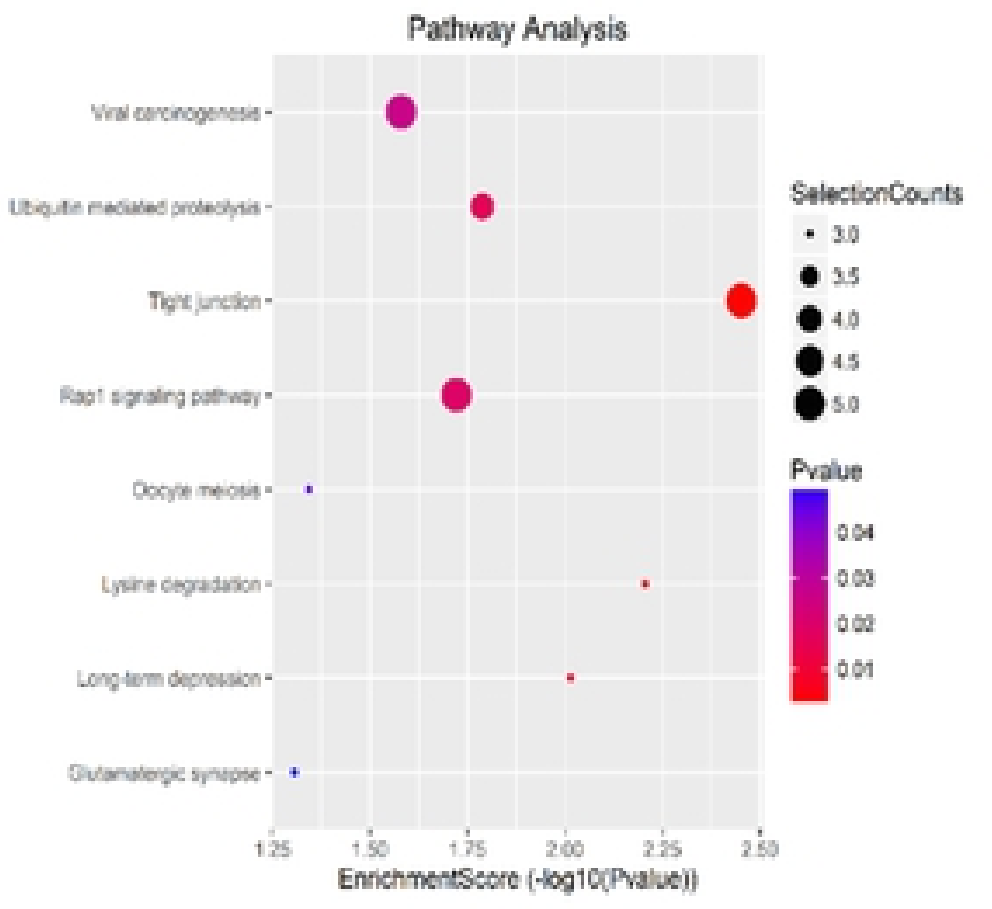

Figure 3 


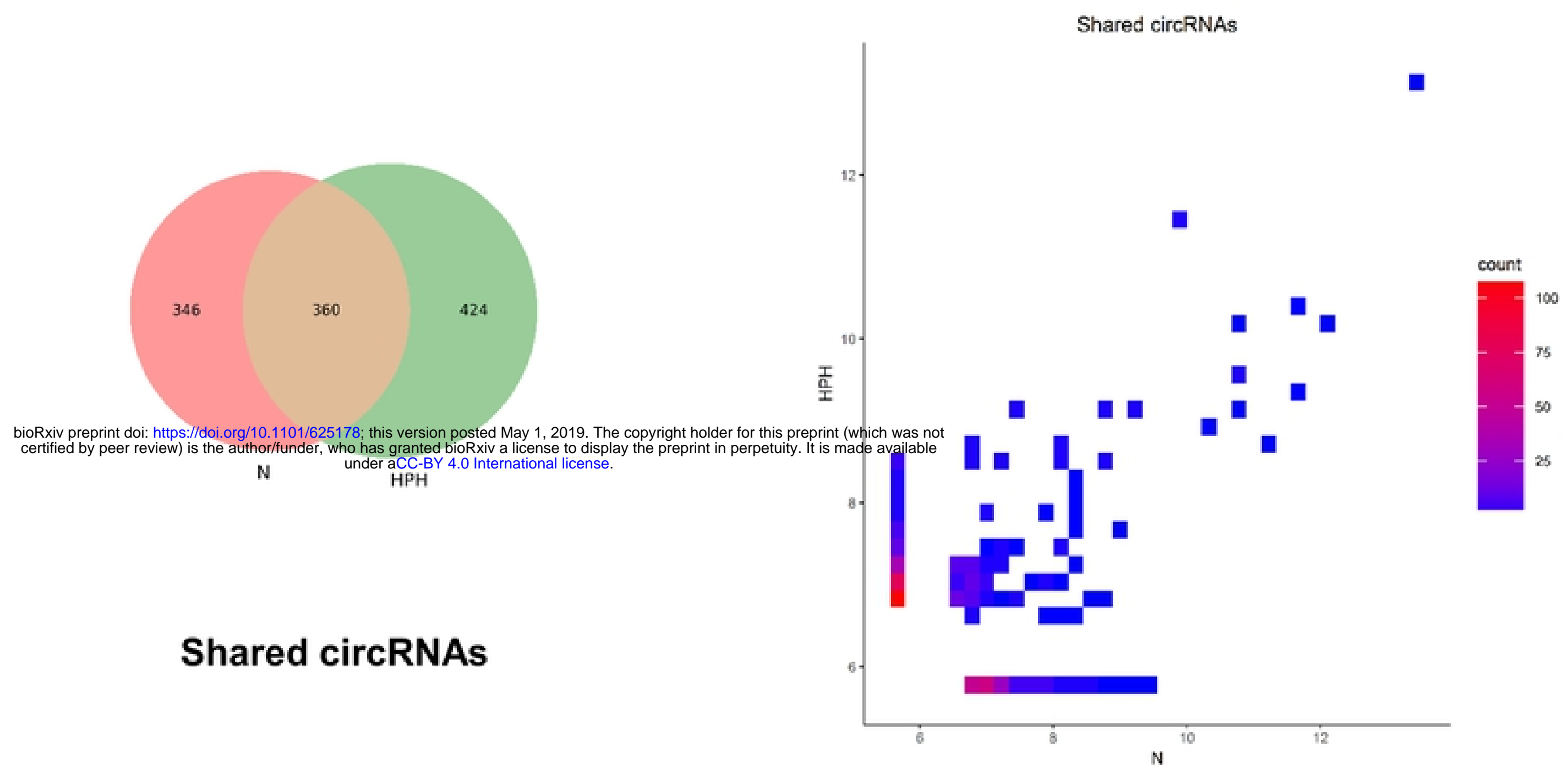

C

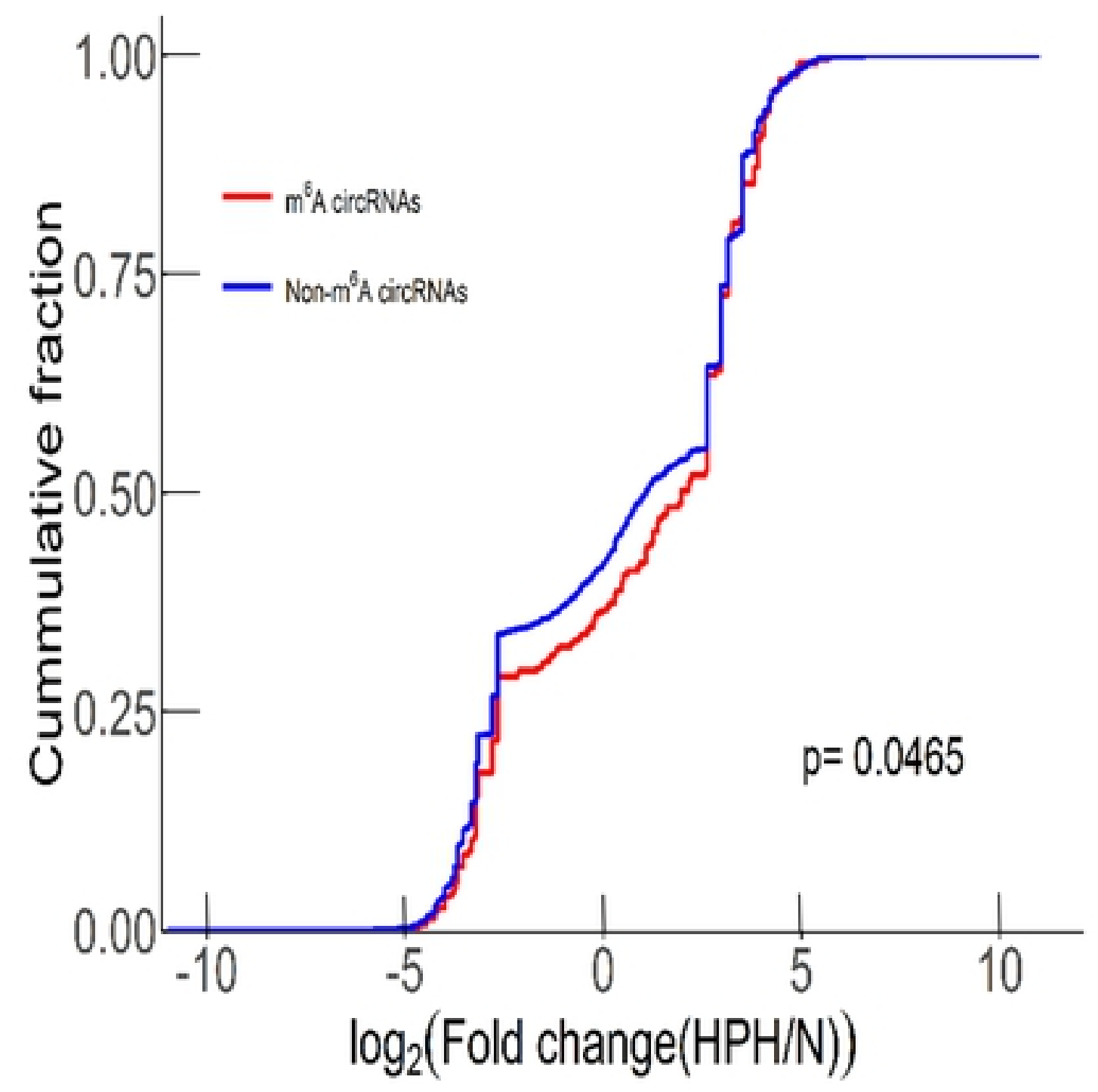

Figure 4 

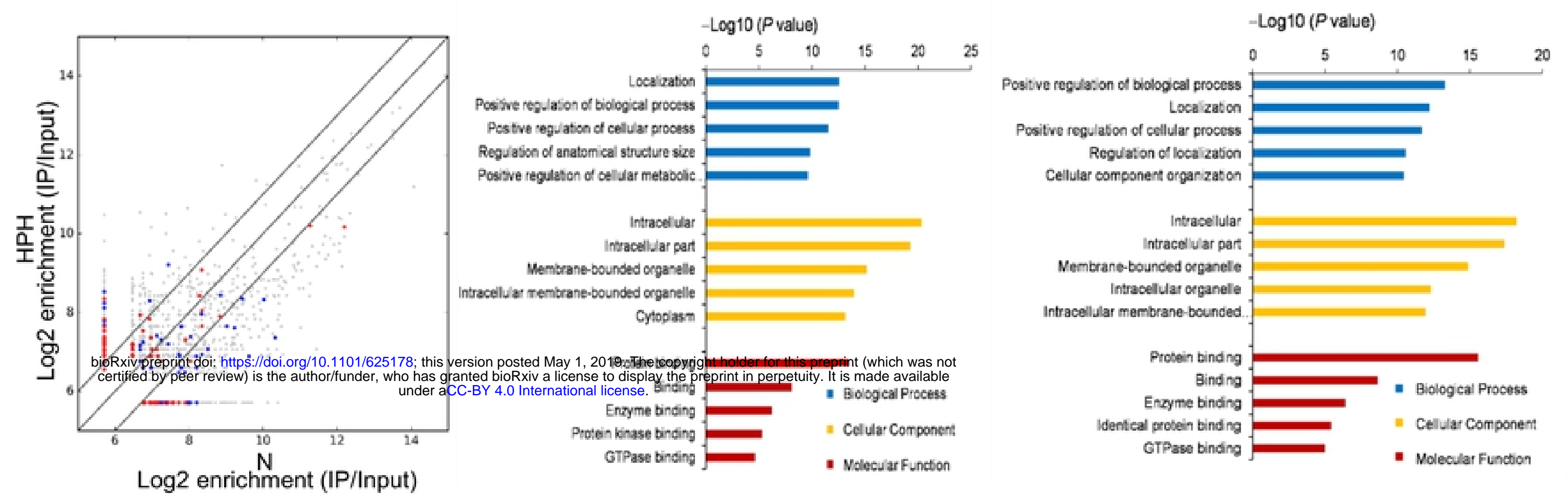

D Methy.up \& exp.up

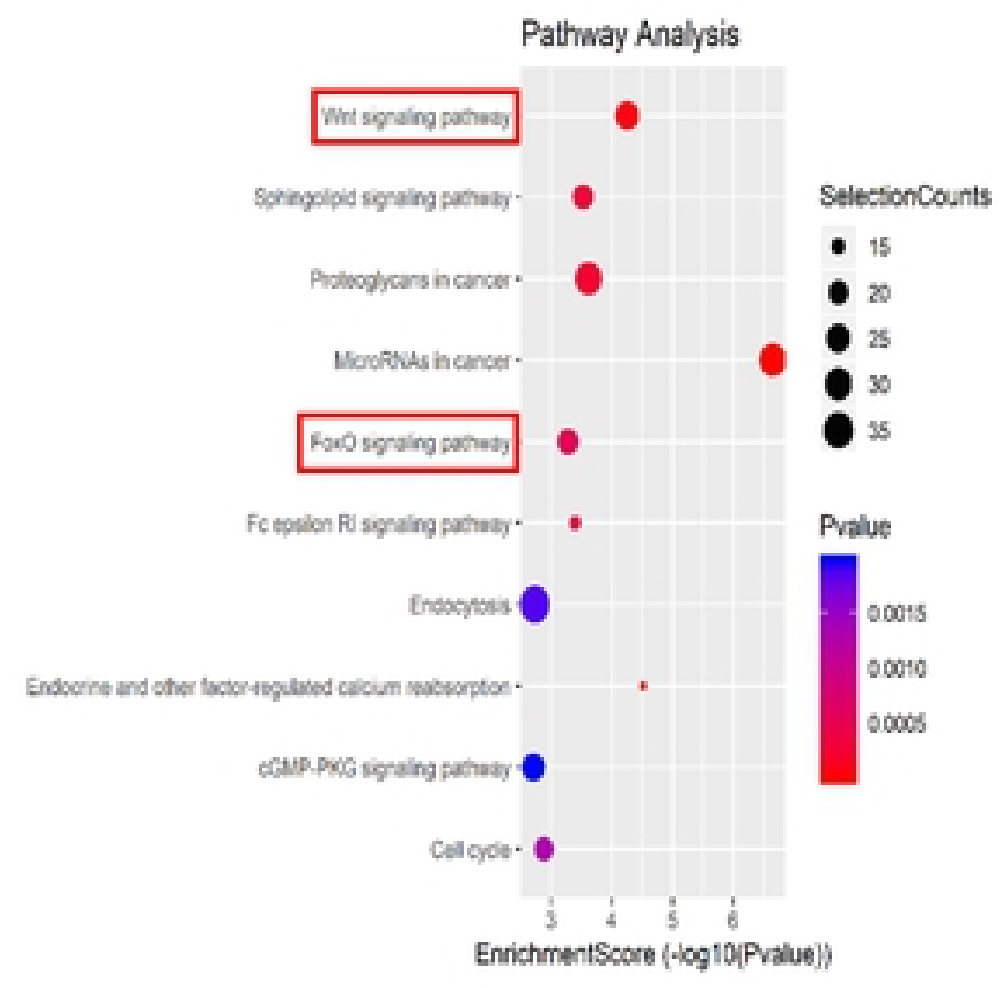

F Methy.up \& exp.up

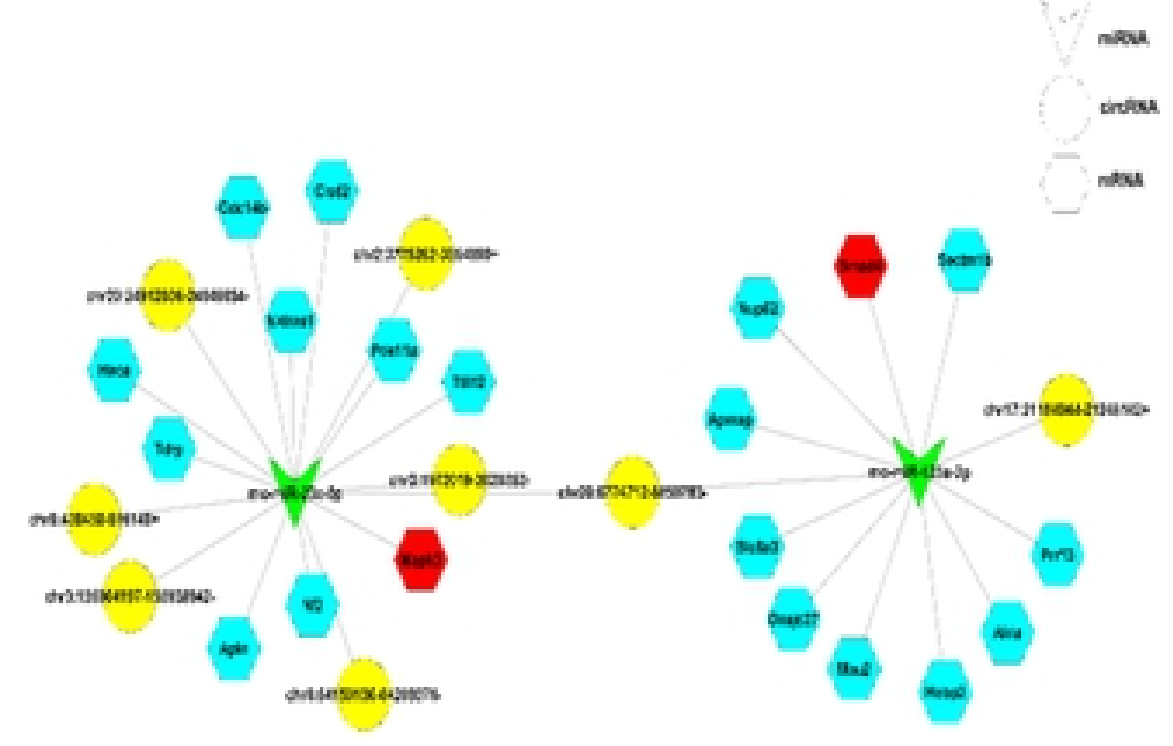

E Methy.down \& exp.down

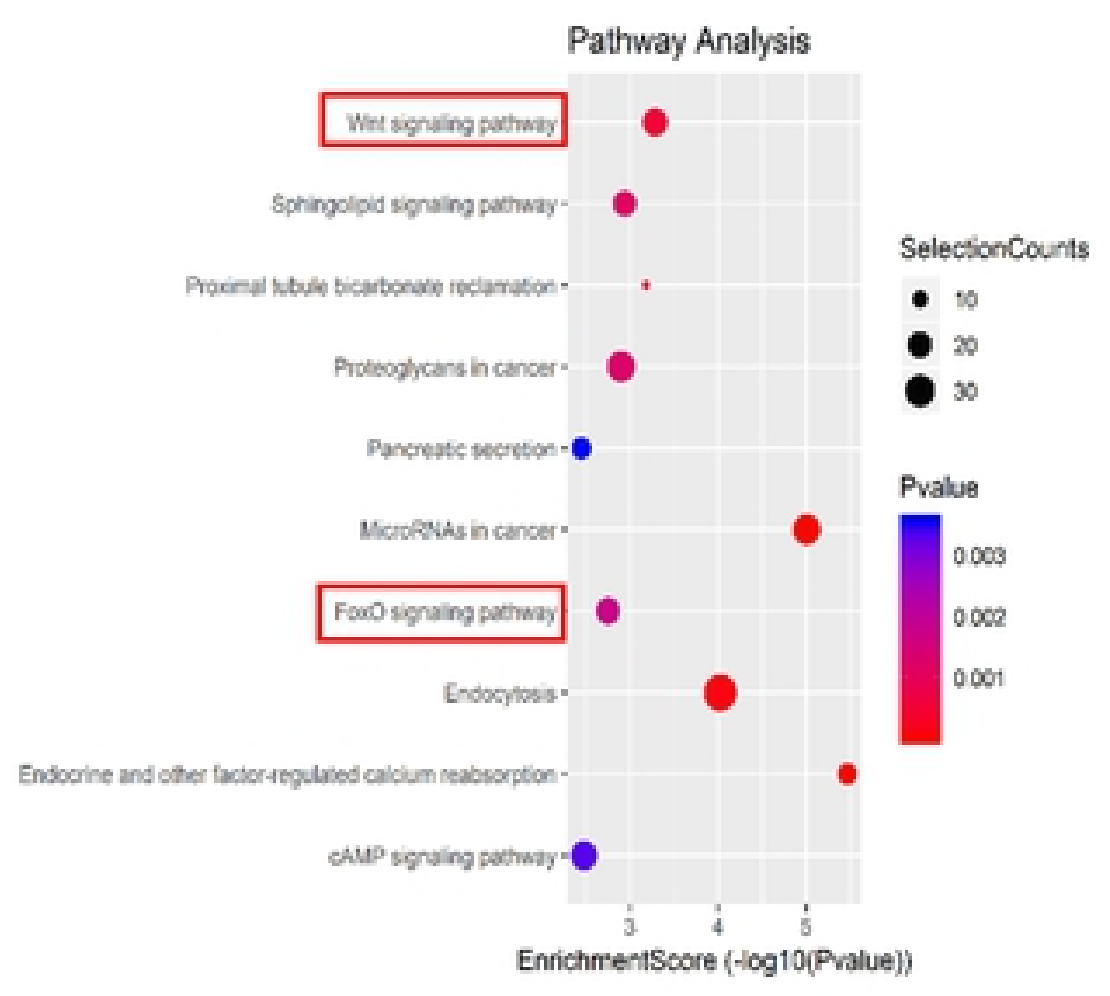

G Methy.down \& exp.down

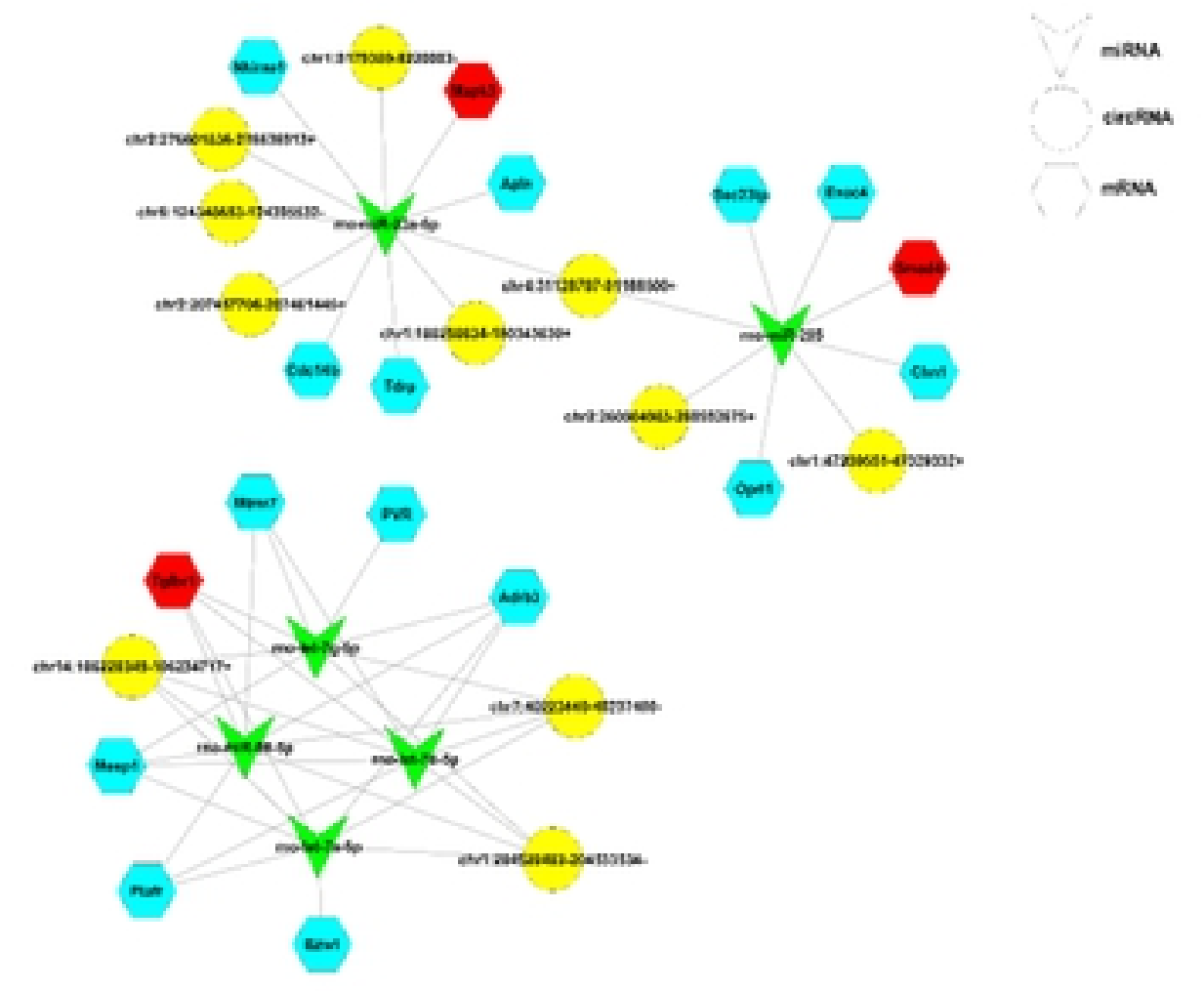

\section{Figure 5}


A

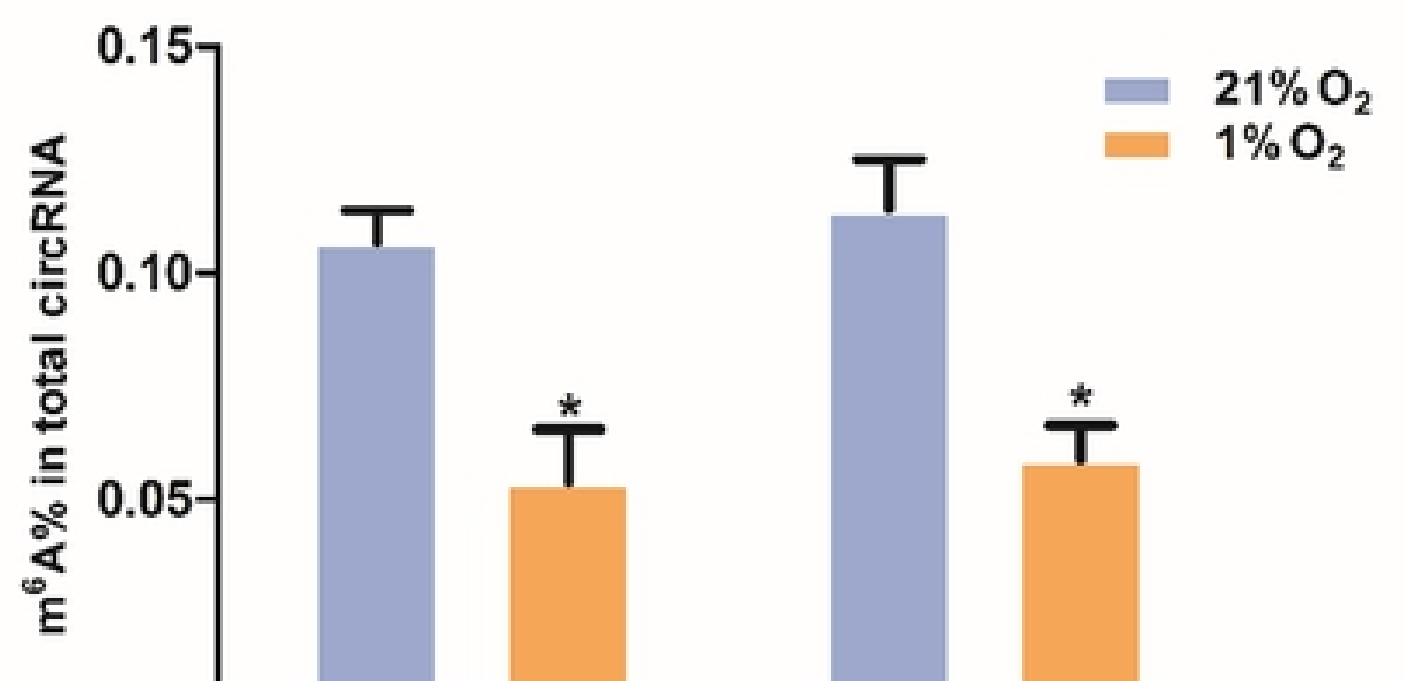

B

\section{Linear Xpo6}

GTGAT4 $\longrightarrow$ AACAG

Exon7 Exon8Exon9

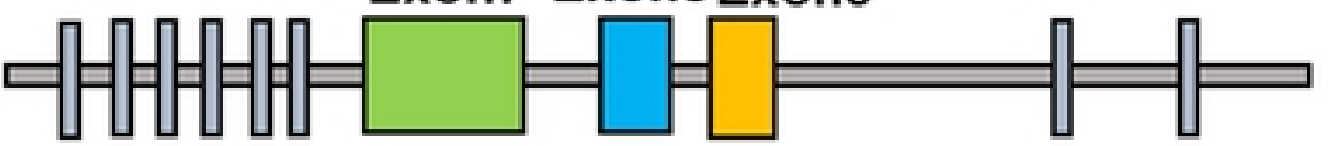

(A)

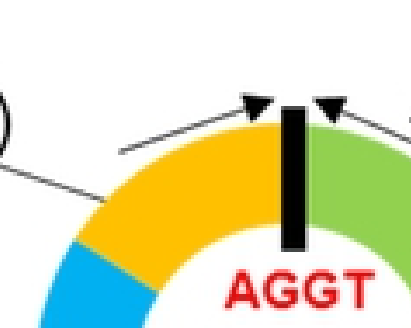

bioRxiy preprin doi: https://doi.org/10.1101/625178; this version posted May 1, 2019. The copyright holder for this preprint (which was not

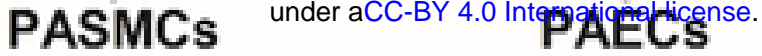

C

\section{Linear mRNA $\Delta$ circRNAs}
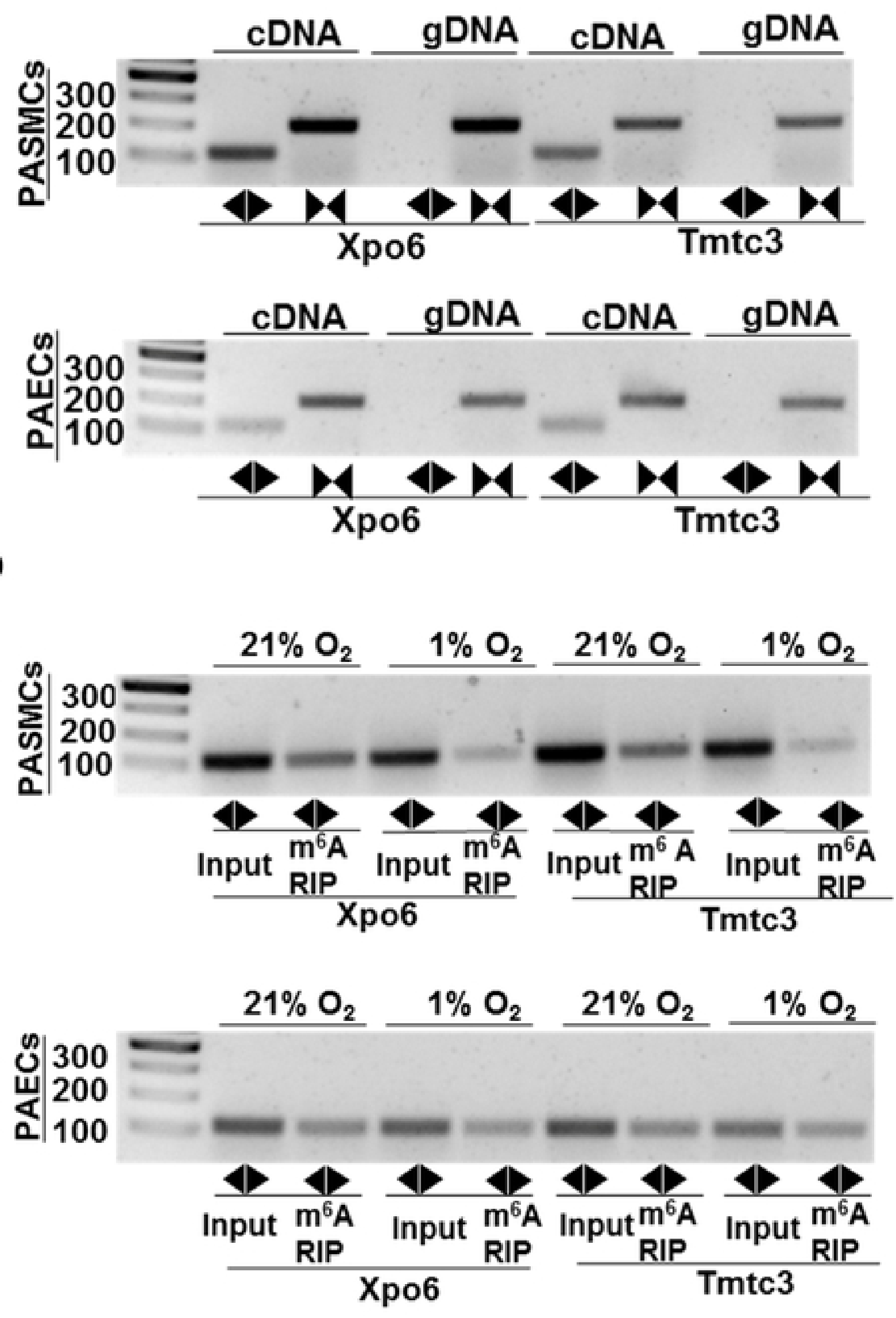

\section{Linear Tmtc3}

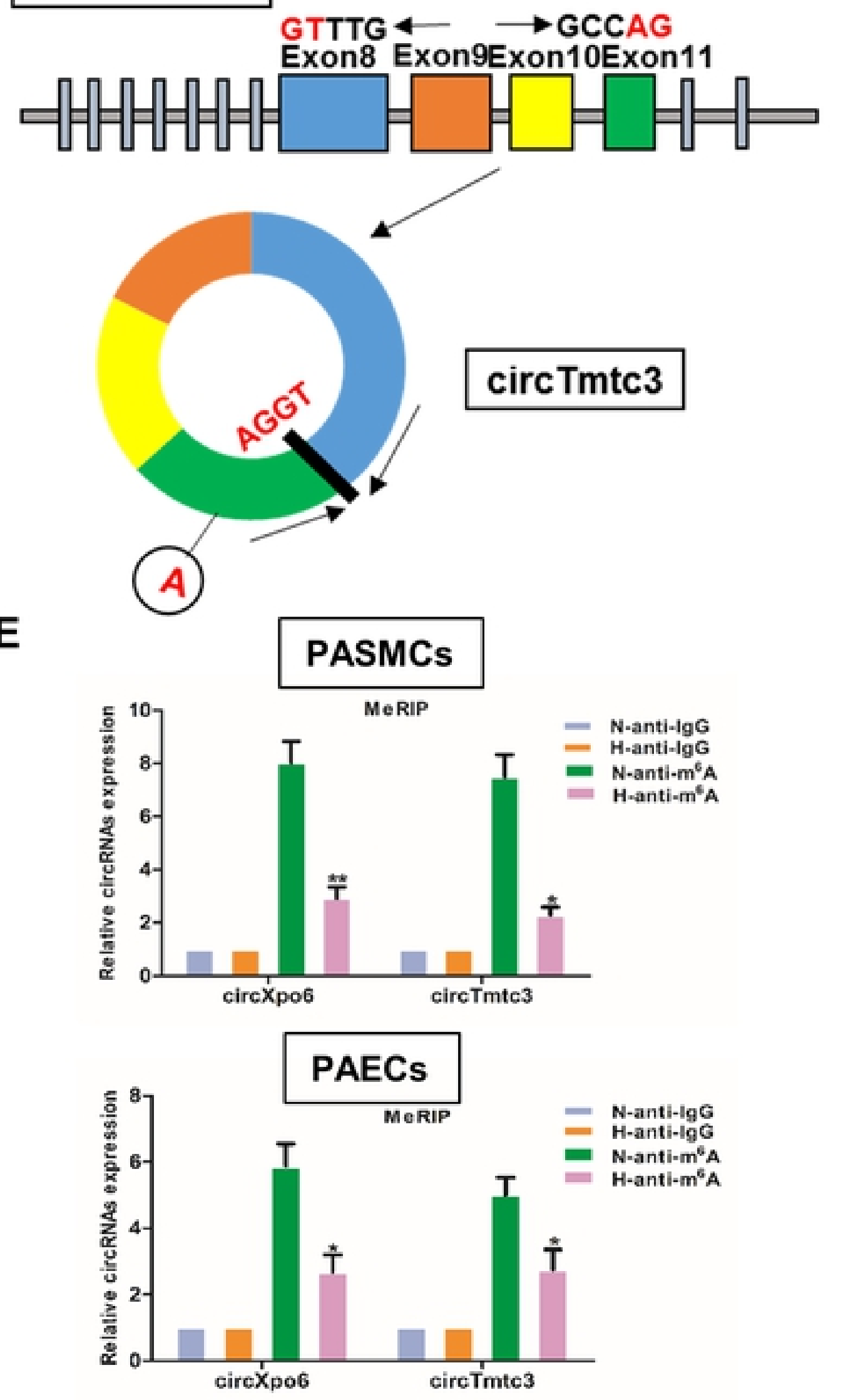

Figure 6 